Discussion Paper No. 03-22

\title{
Economic Implications of
} Alternative Allocation Schemes for Emission Allowances

\section{A Theoretical and Applied Analysis}

Christoph Böhringer and Andreas Lange

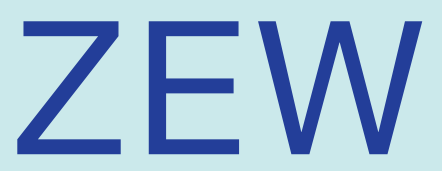

Zentrum für Europäische Wirtschaftsforschung GmbH

Centre for European

Economic Research 
Discussion Paper No. 03-22

\title{
Economic Implications of Alternative Allocation Schemes for Emission Allowances
}

\begin{abstract}
A Theoretical and Applied Analysis
\end{abstract}
Christoph Böhringer and Andreas Lange

Download this ZEW Discussion Paper from our ftp server:

ftp://ftp.zew.de/pub/zew-docs/dp/dp0322.pdf

Die Discussion Papers dienen einer möglichst schnellen Verbreitung von neueren Forschungsarbeiten des ZEW. Die Beiträge liegen in alleiniger Verantwortung der Autoren und stellen nicht notwendigerweise die Meinung des ZEW dar.

Discussion Papers are intended to make results of ZEW research promptly available to other economists in order to encourage discussion and suggestions for revisions. The authors are solely responsible for the contents which do not necessarily represent the opinion of the ZEW. 


\section{Nontechnical Summary}

Environmental regulation schemes often entail some type of compensation to reduce the specific costs for regulated industries. Since compensating mechanisms typically aim at the reduction of adverse production and employment effects in these industries, there is an inherent trade-off for environmental policy between the issue of efficiency and compensation.

In this paper, we analyze the efficiency-compensation trade-off for tradable permit systems where emission allowances are freely allocated to energy-intensive sectors based on either emissions or output. Combining theoretical partial equilibrium analysis with numerical general equilibrium analysis, we find that the trade-off between efficiency and compensation in open trading systems crucially depends on the level of the international permit price. The efficiency costs for ameliorating adverse production and output effects in energy-intensive industries through output-based or emission-based allocation becomes more costly, the higher the international permit price is. The costs reflect foregone gains from permit trading because of permit imports that are too high or, likewise, permit exports that are too small compared to the efficient volumes under auctioned permit systems.

In the open trading system, the output-based allocation rule is distinctly less costly than the emission-based rule to preserve output and employment in energy-intensive sectors. Emission-based allocation is particularly expensive towards higher international permit prices where the implicit subsidies for emission use in energy-intensive sectors produce drastic efficiency losses since they imply high expenditures for carbon permit imports rather than high net revenues from efficient carbon permit exports. Only for small international permit prices is there a relatively small gap in cost-effectiveness (i.e. efficiency costs for reduced production or employment frictions) between the output- and emission-based rule. 


\title{
Economic Implications of Alternative Allocation Schemes for Emission Allowances
}

\section{A Theoretical and Applied Analysis}

\author{
Christoph Böhringer and Andreas Lange \\ boehringer@zew.de, lange@zew.de \\ Centre for European Economic Research (ZEW), Mannheim \\ P.O. Box 103443 \\ D-68034 Mannheim, Germany
}

\begin{abstract}
Political feasibility of emission trading systems may crucially depend on the free initial allocation of emission allowances to energy-intensive industries in order to ameliorate adverse production and employment effects. We investigate the potential trade-off between such compensation and economic efficiency for alternative allocation rules where emission allowances are based on either emissions or output. Based on analytical partial equilibrium and numerical general equilibrium analysis, we show that in open trading systems the trade-off becomes the more severe, the higher the international permit price is. Whenever the permit price can be considered exogenous to firms or industries, the output-based allocation rule is distinctly less costly than the emission-based rule to preserve output and employment in energy-intensive sectors. The reason is that emission-based allocation of allowances not only provides an implicit output subsidy but also lowers the effective price of emission inputs to regulated firms. Emissionbased allocation is particularly expensive towards higher international permit prices where the implicit subsidies to emission use in energy-intensive sectors produce drastic efficiency losses, since they imply high expenditures for carbon permit imports rather than high net revenues from efficient carbon permit exports.
\end{abstract}

JEL classification: D58, H21, H23

Keywords: computable general equilibrium, emissions trading, allowance allocation

Acknowledgements: We would like to thank Tim Hoffmann for valuable research assistance. 


\section{Introduction}

The theory of environmental policy has recommended market-based instruments, i.e. emission taxes or tradable emission permits, on the grounds that they provide a cost-effective means of environmental regulation. The more recent environmental policy design of OECD countries seems to reflect the growing political reception of economic efficiency arguments for market-based instruments (OECD 2001). A prominent example for the market-based course in environmental policy, is the $\mathrm{SO}_{2}$ permit trading scheme that has been implemented under the Clean Air Act during the 90ies in the USA to achieve substantial cuts in nationwide $\mathrm{SO}_{2}$ emissions (Stavins 1998). In the more recent policy debate on greenhouse gas abatement strategies, market-based instruments have further gained popularity vis-à-vis the traditional command-and-control standards. Apart from the relative ease of designing an appropriate tax or permit scheme for $\mathrm{CO}_{2}$ as the most important greenhouse gas, a major reason is the economy-wide base of fossil-fuel use and the associated potentially large efficiency gains from equalizing marginal abatement costs across sources. As a case in point, the European Commission issued a Directive for a carbon trading system within the EU in order to meet its reduction commitments under the Kyoto Protocol (EU 2001).

Economic efficiency can promote political feasibility of environmental regulation, since it may substantially reduce the total adjustment costs. However - as with command-and-control standards political feasibility of market-based instruments depends crucially on the specific cost-incidence for influential regulated parties. Rebating revenues from environmental policies in order to offset part of adjustment costs to influential industries, therefore, has become a central element to the design of marketbased instruments. As for environmental taxation, nearly all schemes involve some form of rebate to dirty industries (OECD 2001). Examples range from the Swedish $\mathrm{NO}_{\mathrm{x}}$ tax, where revenues are rebated to affected power plants in proportion to the amount of energy produced to the design of broader green tax reforms such as in Germany where energy-intensive industries are reimbursed tax payments beyond a certain threshold. Likewise, the implementation of tradable permit systems has always been linked to a free initial distribution of emission allowances rather than through a distribution through auctioning (Stavins 1998). As a matter of fact, grandfathering of $\mathrm{SO}_{2}$ permits to electric utilities has been an important element to the Clean Air Act (Burtraw 1999). In the same vein, the acceptance of the recent EU Directive on carbon trade was approved by member states only under the condition that emission allowances be freely allocated.

However, revenue rebating schemes which might be attractive in positive political economy terms are typically problematic in normative efficiency terms. All policy-relevant rebating schemes involve the imposition of a marginal cost on emissions with an implicit subsidy to output. As has been pointed out by several authors (e.g. Böhringer, Ferris, and Rutherford 1998; Burtraw 1999; Fisher 2001), the latter induces a trade-off between efficiency and compensation in environmental policy.

The aim of this paper is to substantiate this trade-off with quantitative evidence on alternative allocation schemes that are currently considered by EU member states in the context of the EU emissions 
trading directive. Combining stylized partial equilibrium analysis with applied general equilibrium simulations, our main insights can be summarized as follows:

- In a closed trading system, the emission-based allocation rule coincides with the socially efficient solution. The output-based allocation rule ameliorates adverse impacts of emission constraints on production and output of energy-intensive sectors, but this compensation comes at substantial efficiency losses.

- In an open trading system, the output-based allocation rule is distinctly less costly than the emissionbased rule to preserve output and employment in energy-intensive sectors. Emission-based allocation is particularly expensive for higher international permit prices. Here, the implicit subsidies for emission use in energy-intensive sectors produce drastic efficiency losses since they imply high expenditures for carbon permit imports rather than high net revenues from efficient carbon permit exports.

- Only for small international permit prices is there a relatively small gap in cost-effectiveness (i.e. efficiency costs for reduced production or employment frictions) between the output- and emissionbased rule.

- The trade-off between efficiency and compensation in open trading systems depends crucially on the level of the international permit price. The efficiency costs for ameliorating adverse production and output effects in energy-intensive industries through output-based or emission-based allocation becomes more costly the higher the international permit price is. The costs reflect foregone gains from permit trading because of permit imports that are higher than - or likewise permit exports that are small than - the efficient volumes under auctioned permit systems.

The implications of initial permit allocation have been investigated in various numerical analyses. Böhringer, Ferris, and Rutherford (1998) assess the use of free permits - allocated to sectors according to benchmark emission shares - as a means to offset leakage from unilateral carbon abatement. From simulations with a comparative-static computable general equilibrium (CGE) model, they find that grandfathering produces significant efficiency losses compared to auctioned permits because of implicit distortionary output subsidies that are not outweighed by the decline in carbon leakage; at the sectoral level, grandfathered permits are shown to be clearly beneficial to workers and capital owners in energyintensive industries. Jensen and Rasmussen (2000) deepen this distributional perspective in a dynamic CGE model for Denmark. Their analysis confirms high efficiency costs of output-based permit allocation to alleviate adverse adjustment effects of energy-intensive industries. Parry, Williams, and Goulder (1997) highlight the importance of revenue-recycling in the presence of pre-existing tax distortions. Reflecting the literature on "double dividends", they stress the additional losses from environmental policies that do not raise government revenues: The interaction with distortionary taxes make carbon regulation more costly ("tax interaction effect") while revenue-neutral cuts of taxes could ameliorate the overall costs ("revenue-recycling effect"). 
Böhringer and Lange (2003) have developed a simple two-period partial equilibrium model to determine general design rules for optimal dynamic free allocation schemes where the allocation of allowances can be based on output or emission levels of the previous period. They derive second-best allocation schemes based on both previous emissions and output that correspond to a Ramsey rule of optimal tax differentiation: The more inelastic output (emissions) of a firm, the larger the weight to output (emissions) in the allocation rule should be. However, in practice it will hardly be possible to apply such differentiated rules and, thus, concrete policy advice requires the quantification of the economic implications of simple uni-dimensional allocation schemes rather than mixed schemes.

Against this background, our analysis contributes to the literature in several respects. First, we include emission-based approaches in the analysis of alternative allocation rules. Second, we investigate how the economic implications across alternative permit allocation rules change if internal trading schemes are opened to a large emission market with fully elastic supply and demand. This "open system" perspective is particularly relevant in international climate policy given the provision of flexible instruments under the Kyoto Protocol. Third, our numerical analysis reflects key aspects of the EU Directive on a restricted permit market for carbon and thus provides potentially important policy insights.

It should be noted that we investigate the implications of emission- and output-based allocation rules in a static (one-period) setting in which the assignment of allowances is based on firms' current production or emissions. The condensed representation captures the key economic incentives of dynamic allocation schemes (such as the EU Directive) that take historical output or emission levels as a basis for allowance allocation within continuous period-by-period planning. In fact, upcoming firms' decisions will determine the output or emission levels that are "historical" in subsequent periods.

The remainder of this paper is organized as follows. Section 2 describes a simple analytical partial equilibrium model to present the fundamental economic implications of alternative allocations rules. Section 3 describes the numerical general equilibrium framework to quantify the consequences of different allocation rules in a (more) realistic model economy based on empirical data. Section 4 presents the policy simulations and interprets results. Section 5 offers policy conclusions.

\section{Partial Equilibrium Analysis}

In formulating the simple, one-sector partial equilibrium model, we follow the approach by Fischer (2001). A representative firm is assumed to be price taker on both the product and emission markets. Its unit production costs, $c(\mu)$ (decreasing, convex, differentiable), are constant in output but depend on specific emissions $\mu=e / q$. Inverse demand is given by $P(q)$ (decreasing, differentiable). Permissible allowance allocations are fixed by the regulator at some upper (optimal) bound $\bar{E}$. We distinguish two cases: (i) a closed emissions trading system where the price of emission allowances is endogenously determined, and (ii) an open trading system where the price of emission allowances is exogenously given, while it is endogenous in the closed system case. 


\subsection{The Closed System}

In the closed emissions trading system the allowance price is endogenous and the total level of emissions is given by $\bar{E}$. The social planner aims to maximize welfare as the sum of consumer surplus net of production costs:

$$
\begin{aligned}
W & =\int_{0}^{q} P(s) d s-c(\mu) q \\
\text { s.t. } \mu q & =\bar{E}
\end{aligned}
$$

This yields the following first-order conditions:

$$
\begin{aligned}
P(q) & =c(\mu)-c^{\prime}(\mu) \mu \\
\mu q & =\bar{E}
\end{aligned}
$$

Equation (2) states that at the optimal production level, the marginal benefit of another unit of production must compensate for the social costs of producing another output unit. The shadow price of an emission unit is given by $\tau=-c^{\prime}(\mu)$. It determines the optimal emission rate such that the marginal value of an additional emission unit (the marginal costs of the emission externality) equals the marginal cost of emissions reduction. The optimal solution can easily be decentralized by imposing an explicit emission tax at rate $\tau$ or by auctioning off the allowances $\bar{E}$.

As stressed by the "double dividend" literature, the revenues that accrue from the taxation or auctioning could be used to reduce some initial distortionary tax while keeping public good provision constant. In this way, the direct cost of emission constraints - neglecting external costs - could be reduced yielding the so-called weak double-dividend (Goulder 1995). Yet, the regulator may only be able to gain political feasibility if revenues are directly rebated to regulated firms. For example, the EU Directive on emissions trading prescribes the free allocation of allowances to energy-intensive firms as a prerequisite for being approved from the EU member states.

From an efficiency point of view, lump-sum transfers which correspond to allocations of allowances that do not depend on firm-specific decisions would be second-best. However, under distributional equity, such transfers are most likely undesirable since they are typically channeled to stakeholders in these industries without lowering adverse effects on employment (production), i.e. workers' displacement. Therefore, allowance allocation schemes as well as tax revenue rebating schemes are usually linked to firms' output or emission levels. Since both - output and emissions - are control variables of the firm, the allocation of permits conditioned on output or emissions work as implicit output subsidies that affect firms' behavior and tend to reduce economic efficiency of the environmental policy.

In formal terms, if a firm's allocation of allowances is specified as $\lambda_{q} q$ for output-based and $\lambda_{e} \mu q$ for the emissions-based rules, the individual firm maximizes profits:

$$
\Pi=P q-c(\mu) q-\tau\left(\lambda_{\mathrm{q}} q+\lambda_{\mathrm{e}} \mu q-\bar{E}\right)
$$


In the closed system, the subsidy rates $\lambda_{\mathrm{e}}$ and $\lambda_{\mathrm{q}}$ are endogenous. In equilibrium, they satisfy $\lambda_{e}=\bar{E} / \mu q$ and $\lambda_{q}=0$ for the emissions-based allocation rule whereas the output-based rule is given by $\lambda_{e}=0$ and $\lambda_{q}=\bar{E} / q$. (N.B.: The competitive assumption requires that firms take the subsidization rate as given). Table 1 summarizes the associated first-order and equilibrium conditions of the decentralized firm.

Table 1: First-order and equilibrium conditions of a decentralized firm in the closed trading system

\section{Output-based rule (q-based) $\quad$ Emissions-based rule (e-based)}

\begin{tabular}{|c|c|}
\hline \multicolumn{2}{|c|}{ First-order conditions } \\
\hline $\begin{aligned} P(q) & =c(\mu)+\tau \mu-\lambda_{q} \tau \\
\tau & =-c^{\prime}(\mu)\end{aligned}$ & $\begin{aligned} P(q) & =c(\mu)+\tau \mu\left(1-\lambda_{e}\right) \\
\tau\left(1-\lambda_{e}\right) & =-c^{\prime}(\mu)\end{aligned}$ \\
\hline \multicolumn{2}{|c|}{ Equilibrium conditions } \\
\hline $\begin{aligned} P(q) & =c(\mu) \\
\mu q & =\bar{E}\end{aligned}$ & $\begin{aligned} P(q) & =c(\mu)-c^{\prime}(\mu) \mu \\
\mu q & =\bar{E}\end{aligned}$ \\
\hline
\end{tabular}

By comparing the equilibrium conditions with the social optimum (2), we can immediately see that the emissions-based rule warrants efficiency. The output-based rule, however, distorts specific emissions and the output level: Here, the equilibrium output price equals marginal private costs. Basically, the possibility of cutting emissions by a reduction of output is not taken into account. Due to the presence of the output subsidy, the output level is larger compared to the efficient solution, $q^{q}>q^{*}$, while the specific emissions are smaller, $\mu^{q}<\mu^{*}$ in order to achieve the required emission levels. As a result, marginal cost of abatement will be higher.

Figure 1(a) illustrates the determination of specific emissions and output levels according to the equilibrium conditions for both the output- and the emissions-based rule. Conditions for the latter rule coincide with the social optimum. Figure 1(b) visualizes the welfare effects in the $p-q$ diagram. Compared to the social optimum, the welfare effects of the output-based rule are twofold: On the one hand, there is some additional consumer surplus due to the increased production level (marked by "+" in Figure 1(b)). On the other hand, there is a loss of welfare due to the higher social cost of production (marked by "_." in Figure 1(b)). 
Figure 1: Implications of allocation schemes in the closed trading system

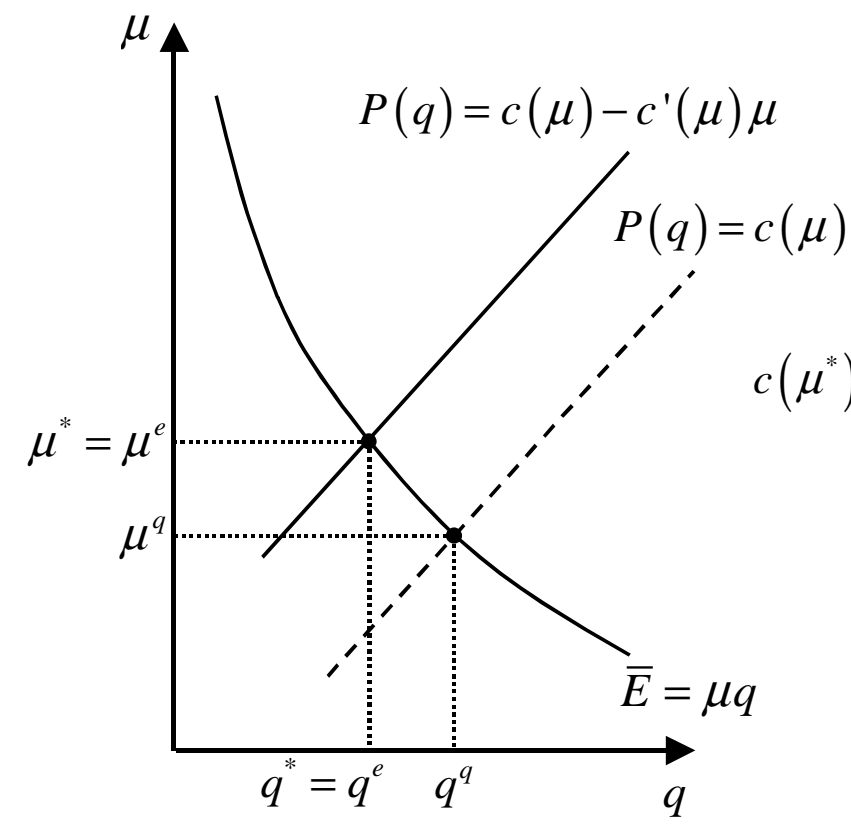

(a)

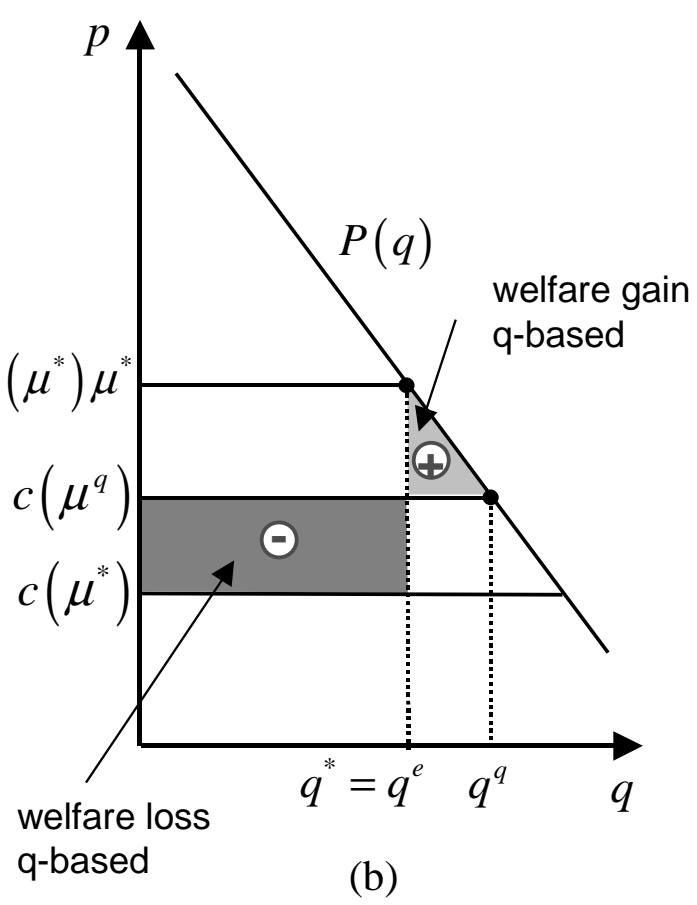

(b)

\subsection{The Open System}

We now turn to the case of a (small) open emission trading system where countries perceive a fixed international market price $\tau$ for emission allowances. As a concrete example, the EU carbon trading system envisaged under the EU Directive can be considered as an open system in which the single EU country views the EU permit market as sufficiently large to take the permit price as exogenous. Moreover, the EU market will be opened to non-EU regions rendering effectively fully elastic import demand and export supply.

In the open system, the social planner maximizes overall welfare

$$
W=\int_{0}^{q} P(s) d s-c(\mu) q-\tau(\mu q-\bar{E})
$$

leading to the following first-order conditions:

$$
\begin{gathered}
P(q)=c(\mu)+\tau \mu \\
\tau=-c^{\prime}(\mu)
\end{gathered}
$$

Again, we consider the welfare effects of output- and emission-based allocation rules. Here, the first-order conditions for the profit-maximizing individual firm are identical to those in the closed system. The equilibrium conditions, however, change, since the allowance price $\tau$ is fixed by the world market. Table 2 summarizes the first-order and equilibrium conditions. Comparing the social optimum (5) with the equilibrium conditions, we see that the specific emissions are not distorted if the allocation of allowances is output-based. The output level, however, is chosen too high due to the subsidies on output. Therefore, for output-based allocations, welfare losses occur only due to the distortion of output. 
Table 2: First-order and equilibrium conditions of a decentralized firm in the closed trading system

\begin{tabular}{cc}
\hline Output-based rule (q-based) & Emissions-based rule (e-based) \\
\hline \multicolumn{2}{c}{ First-order conditions } \\
$P(q)=c(\mu)+\tau \mu-\lambda_{q} \tau$ & $\begin{array}{c}P(q)=c(\mu)+\tau \mu-\lambda_{e} \mu \tau \\
\tau=-c^{\prime}(\mu)\end{array}$ \\
\hline \multicolumn{2}{c}{ Equilibrium conditions } \\
$P(q)=c(\mu)+\tau \mu-\tau E / q$ \\
$\tau=-c^{\prime}(\mu)$ \\
$P(1-\bar{E} /(\mu q))=-c^{\prime}(\mu)$
\end{tabular}

For the emissions-based rule, however, there is an additional distortion of the specific emission level: Due to the subsidies on emissions, specific emissions are chosen at a larger level than optimal. Note that in the case, where $\mu q<\bar{E}$, i.e. the country exports emissions allowances, the firms chooses the maximal specific emissions $\left(-c^{\prime}(\mu)=0\right)$. As a result, the net effect on the choice of the output level is ambiguous: On the one hand, the distortion of the specific emission rate induces an increase of the social marginal production costs $(c(\mu)+\tau \mu)$, thereby reducing the output level. On the other hand, the emissionsbased rule implicitly subsidizes output at the rate $\tau \bar{E} / q$, thereby increasing the output level. Welfare losses can thus be decomposed in two components: (i) higher social costs per unit of output, $(c(\mu)+\tau \mu)$, and (ii) a distorted output level.

The choices of output and specific emissions for the social optimum as well as for emissions- and output-based allocations are illustrated in Figure 2(a). Figure 2(b) visualizes the welfare losses for the distortionary allocation rules. In our example, the implicit subsidies on output imply that output-levels are too high for both allocation schemes.

In the open system, the excess costs that arise due to the use of output- or emissions-based allocation schemes depend on the exogenous price for emission allowances. In order to study the economic implications of changes in international permit prices, we first consider the aggregate emission levels resulting in the respective cases and then assess the welfare effects. Straightforward differentiation of the equilibrium conditions by $\tau$ yield the relationships as summarized in Table 3 .

In the social optimum, it is obvious that total emissions decrease in $\tau$. It becomes more and more profitable to sell the allowances at the international market at price $\tau$. For the output-based rule, total emissions decrease if the country is a net buyer of allowances $(\mu q>\bar{E})$, whereas the change is ambiguous if $\mu q<\bar{E}$ (which is likely for larger $\tau$ ). For the emissions-based allocation rule, total emissions can only decrease in $\tau$ if and only if the country is a net buyer of allowances. Thus, if for $\tau=0$, the country is a net buyer, it will remain a net buyer for all $\tau$. Its total emissions converge to the emissions assignment $\bar{E}$. 
Figure 2: Implications of allocation schemes in the open trading system

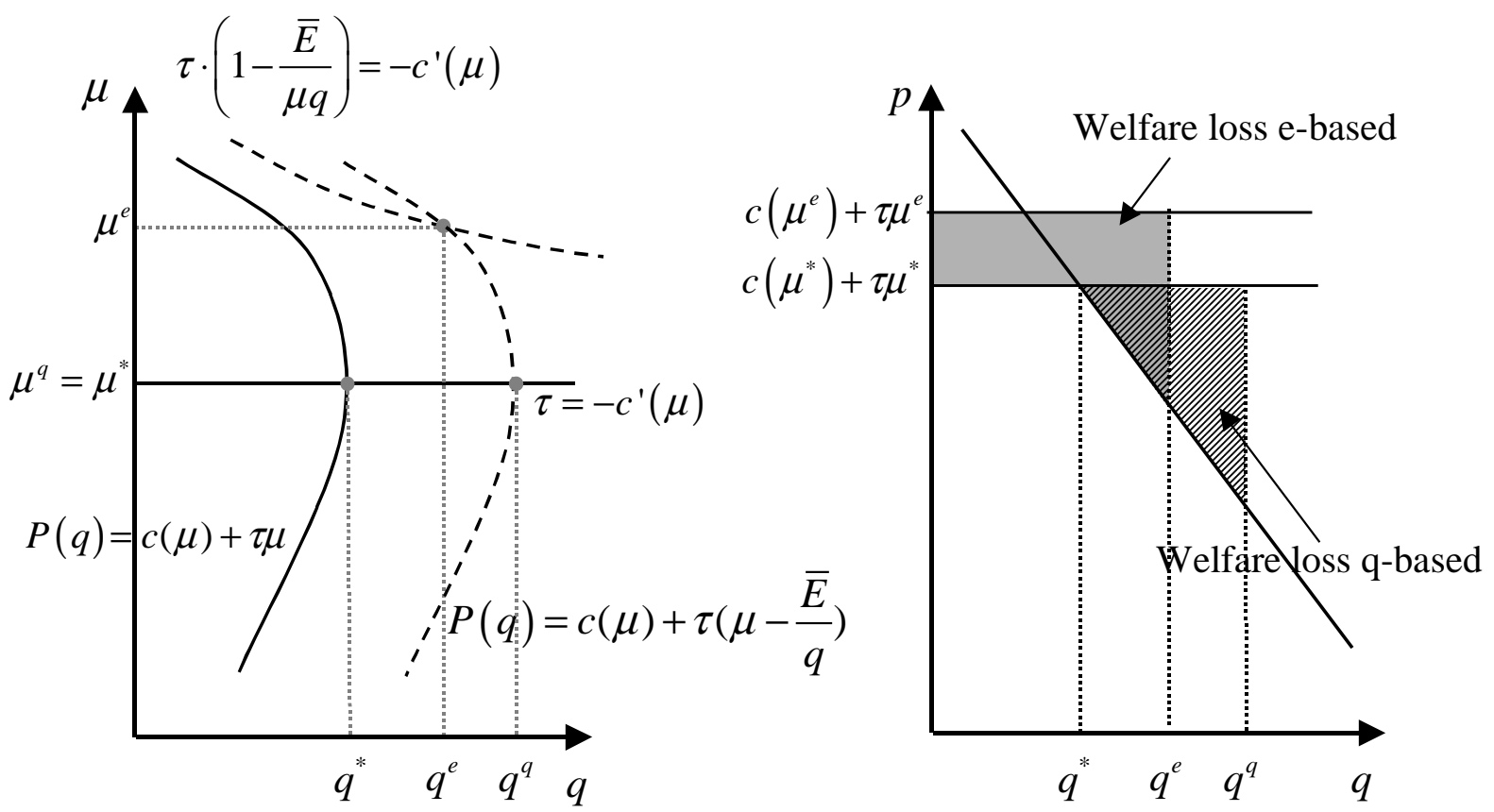

Table 3: Sensitivity of emission and welfare w.r.t. the international permit price

\begin{tabular}{|c|c|c|}
\hline & Emission levels $\frac{\partial(\mu q)}{\partial \tau}$ & Welfare $\frac{\partial W^{o p t}}{\partial \tau}$ \\
\hline $\begin{array}{l}\text { Social } \\
\text { optimum }\end{array}$ & $-\frac{q}{c^{\prime \prime}}+\frac{\mu^{2}}{P^{\prime}}<0$ & $-(\mu q-\bar{E})$ \\
\hline $\begin{array}{l}\text { Output- } \\
\text { based rule }\end{array}$ & $-\frac{q}{c^{\prime \prime}}+(\mu-\bar{E} / q) \frac{\mu}{P^{\prime}-\tau \bar{E} / q^{2}}$ & $-(\mu q-\bar{E}) \frac{P^{\prime}}{P^{\prime}-\tau \bar{E} / q^{2}}$ \\
\hline $\begin{array}{l}\text { Emission- } \\
\text { based rule }\end{array}$ & $(\mu-\bar{E} / q) \frac{\mu c^{\prime \prime}-q P^{\prime} / \mu}{P^{\prime} c^{\prime \prime}+P^{\prime} \tau \bar{E} /\left(\mu^{2} q\right)-c^{\prime \prime} \tau \bar{E} / q^{2}}$ & $-(\mu q-\bar{E}) \frac{P^{\prime} c^{\prime \prime}}{P^{\prime} c^{\prime \prime}+P^{\prime} \tau \bar{E} /\left(\mu^{2} q\right)-c^{\prime \prime} \tau \bar{E} / q}$ \\
\hline
\end{tabular}

Referring to welfare, it is obvious that a country benefits from higher allowance prices in all three cases if it is a net seller of allowances, but it suffers if it relies on buying allowances. As already discussed, the specific allocation rule determines whether and at which international permit price the switch from buying to selling allowances will occur. If allowances are free, i.e. $\tau=0$, no distortions will result from choosing emissions- or output-based rules. By continuity, for small exogenous emissions prices, welfare losses due to the application of the two rules are small and similar. Towards larger $\tau$, however, the differences between the rules become more severe. Thus, assuming that at $\tau=0$ the country is a net buyer, the welfare levels will decrease in $\tau$ for small levels of $\tau$ in all three cases. For the social optimum and the output-based rule, there will be a switch to selling allowances after which welfare will increase. For the emissions-based rule, however, welfare will continue to decrease. Hence, even if for 
small levels of $\tau$, the choice of the allocation scheme does not have severe welfare consequences, the output-based rule will be favored towards higher emission prices.

\section{Numerical General Equilibrium Analysis}

The partial equilibrium analysis provides important insights into the economic incentives and equilibrium implications for alternative allocation schemes. However, the framework is highly stylized to keep analytical tractability. As soon as certain real-world complexities are taken into account, e.g. a more detailed production structure or various market interactions, analytical solutions are no longer available and numerical solutions methods are required. In this context, computable general equilibrium (CGE) models have become the standard tool for applied analysis of measures in various policy domains. Its main virtue is the micro-consistent representation of direct effects as well as of important indirect feedbacks and spillovers induced by exogenous policy changes. The simultaneous explanation of the origin and spending of the agents' income makes it possible to address both economy-wide efficiency as well as distributional impacts of policy interference. In order to quantify the relevance of our analytical insights and provide „real“ numbers for the policy debate, we employ a standard CGE model of open economies (see e.g. Böhringer and Vogt 2003). A non-technical summary of the generic model structure and its parameterization is provided below. The detailed algebraic exposition is presented in Appendix A.

\subsection{Non-Technical Model Summary}

Figure 3 provides a diagrammatic structure of a generic multi-sector open-economy model designed for the investigation of economic impacts from carbon abatement policies. Primary factors of

region $r$ include labor $\bar{L}_{r}$, capital $\bar{K}_{r}$ and fossil-fuel resources $\bar{Q}_{f f, r}$. Labor and capital are intersectorally mobile within a region, but cannot move between regions. A specific resource is used in the production of crude oil, coal and gas, resulting in upward sloping supply schedules.

Production $Y_{i r}$ of commodities $i$ in region $r$, other than primary fossil fuels, is captured by aggregate production functions which characterize technology through substitution possibilities between various inputs. Nested constant elasticity of substitution (CES) cost functions with three levels are employed to specify the substitution possibilities in domestic production between capital, labor, energy and non-energy, intermediate inputs, i.e. material. At the top level, non-energy inputs are employed in fixed proportions with an aggregate of energy, capital and labor. At the second level, a CES function describes the substitution possibilities between the energy aggregate and the aggregate of labor and capital. Finally, at the third level, capital and labor trade off with a constant elasticity of substitution. As to the formation of the energy aggregate, we allow sufficient levels of nesting to permit substitution between primary energy types, as well as substitution between a primary energy composite and secondary energy, i.e. electricity. 


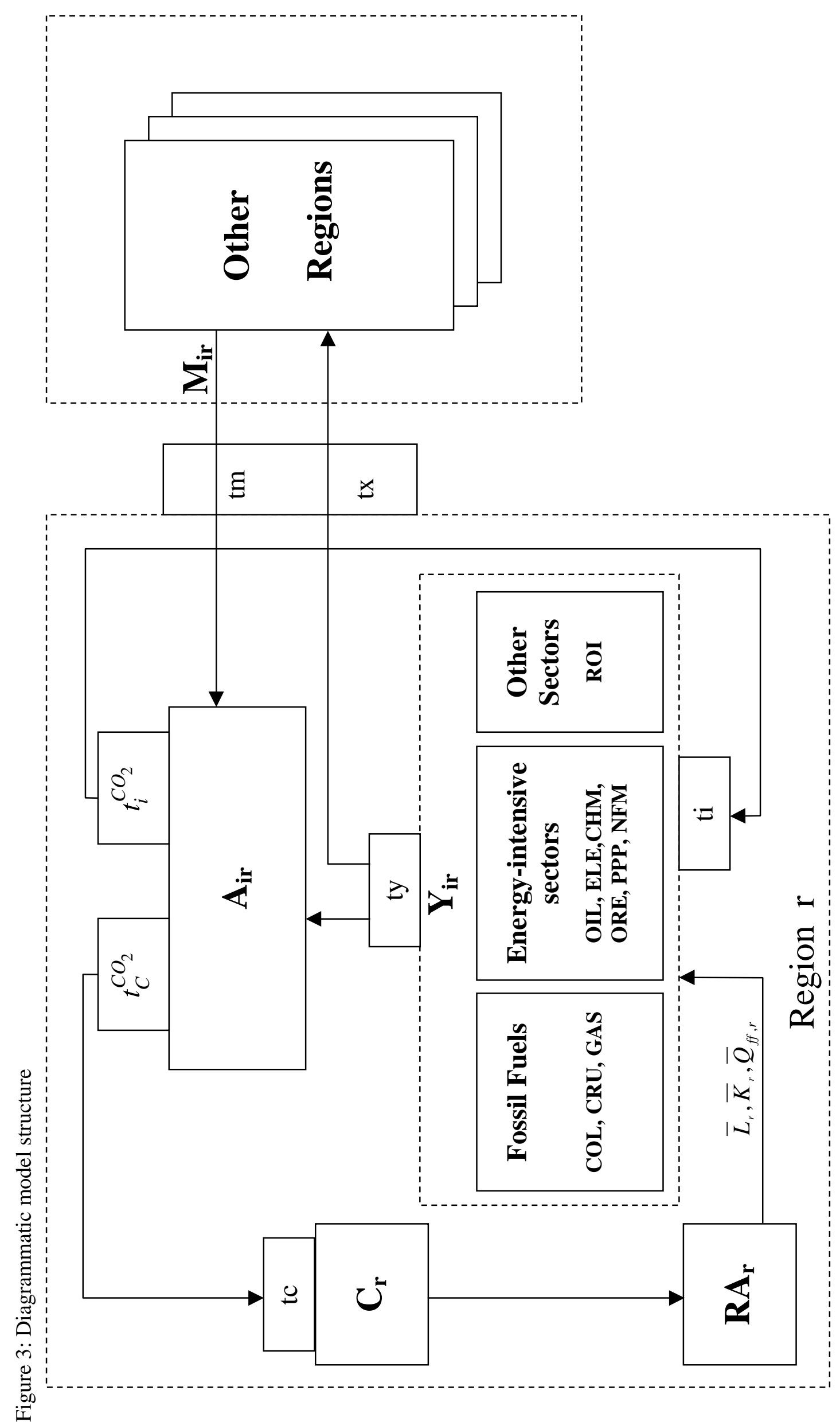


In the production of fossil fuels, all inputs, except for the sector-specific fossil fuel resource, are aggregated in fixed proportions at the lower nest. At the top level, this aggregate trades off with the sector-specific fossil fuel resource at a constant elasticity of substitution. The latter is calibrated in consistency with an exogenously given price elasticity of fossil fuel supply.

Final demand $C_{r}$ in each region is determined by a representative agent $R A_{r}$, who maximizes utility subject to a budget constraint with fixed investment. Total income of the representative household consists of factor income and tax revenues. Final demand of the representative agent is given as a CES composite which combines consumption of an energy aggregate with a non-energy consumption bundle. Substitution patterns within the non-energy consumption bundle are reflected via Cobb-Douglas functions. The energy aggregate in final demand consists of the various energy goods trading off at a constant elasticity of substitution.

All goods used on the domestic market in intermediate and final demand correspond to a CES composite $A_{i r}$ of the domestically produced variety and a CES import aggregate $M_{i r}$ of the same variety from the other regions, the so-called Armington good (Armington 1969). Domestic production either enters the formation of the Armington good or is exported to satisfy the import demand of other regions. The balance of payment constraint, which is warranted through flexible exchange rates, incorporates the benchmark trade deficit or surplus for each region.

\subsection{Data and Calibration}

In comparative-static CGE policy analysis, the effects of policy interference are measured with respect to a reference situation - usually termed business-as-usual (BaU) where no policy changes apply. The reference situation is captured by economic transactions in a particular benchmark year. As is customary in applied general equilibrium analysis, benchmark quantities and prices - together with exogenous elasticities (see Table A.6 in Appendix A) - determine the parameters of the functional forms. For this model calibration, we employ the GTAP-5E database which provides a consistent representation of energy markets in physical units and detailed accounts of regional production and consumption as well as bilateral trade flows for 23 commodities (sectors) and 50 regions (McDougall et al. 1998).

For our applied analysis of carbon abatement under alternative permit allocation schemes, we have aggregated the 23 sectors into 10 composite sectors. Energy goods in the model include primary energy carriers (coal (COL), gas (GAS), crude oil (CRU)) and secondary energy carriers (refined oil products (OIL) and electricity (ELE)). This disaggregation is essential in order to distinguish energy goods by carbon intensity and by the 
degree of substitutability. Moreover, we explicitly represent four energy-intensive (nonenergy) sectors that - in addition to the secondary energy carriers - are the prime candidates for a restricted permit trading system (as is the case for the EU Directive on the European carbon trading system). The remaining production and services are attributed to a composite industry that produces a non-energy-intensive macro good $(\mathrm{Y})$.

Table 4: Overview of sectors (commodities)

\begin{tabular}{ll}
\hline \multicolumn{2}{l}{ Sectors } \\
\hline COL & \\
CRU & Coal \\
GAS & Crude oil \\
Energy-intensive sectors & (EIS) \\
OIL & Refined oil products \\
ELE & Electricity \\
CHM & Chemical products \\
ORE & Iron and steel \\
PPP & Paper, pulp, and printing \\
NFM & Non-ferrous metals \\
Remaining manufactures & and services \\
ROI & Rest of Industry \\
\hline
\end{tabular}

With respect to the regional disaggregation, we restrict our core simulations to a single-region open-economy setting (see section 5.3 for sensitivity analysis with respect to a multi-lateral setting): Detailed domestic production and consumption patterns are described for one region (selected from the set of 50 regions in the GTAP database) while the representation of the Rest of the World is condensed by infinitely elastic export supply and import demand. Thus, the single region is assumed to behave as price-taker on international markets.

\section{Scenario and Results}

\subsection{Scenarios}

In our numerical simulations, we consider a single open economy that is committed to some exogenous emission cutback relative to the benchmark emission level. To reflect the broad range of alternative policy options, we distinguish six abatement scenarios four of which consider an emissions trading system restricted to energy-intensive sectors. We are then faced with the question of how many emission rights should be allocated to these 
sectors. In our simulations, we assume that total emission allowances for the restricted market equal the emissions of these sectors that would occur in the presence of a uniform carbon tax which constitutes their optimal emission level for a domestic abatement policy (see scenario $N T R)$. Revenues from carbon taxes or auctioned permits are rebated lump-sum to the representative agent. Under the emission-based rule, allowances $\bar{E}$ are freely allocated to energy-intensive sectors in proportion to their emissions. Under the output-based rule, allowances $\bar{E}$ are freely allocated to energy-intensive sectors in proportion to their output weighted with the sector-specific historical performance standard, i.e. the emission-output ratio for the benchmark year.

The first set of two scenarios considers domestic action only:

- NTR: The government sets a uniform domestic carbon tax sufficiently high to meet the national reduction targets. The NTR simulation reflects the cost-efficient policy if no cross-border emissions trading is possible. It thus delivers a reference point for the magnitude of efficiency gains from where-flexibility (addressed by the second set of scenarios).

- DOMESTIC: Energy-intensive sectors form a restricted domestic permit market with permits allocated across these sectors according to the output-based rule. This scenario reflects the setting of a restricted domestic allowance trading system as analyzed in section 2.1. The remaining segments of the economy are subject to a carbon tax that warrants compliance with the overall domestic reduction target.

The second set of four scenarios takes into account international emissions trading under alternative settings for trade-eligible sectors and permit allocation schemes:

- TRD: The government sets domestic carbon tax at the level of the international permit price, selling emission rights in excess of the domestic reduction target or buying emission rights to fulfill the emission reduction requirements. The TRD scenario provides the overall cost-efficient solution.

The remaining three scenarios restrict international emissions trading to the energyintensive sectors and differ only with respect to the allocation of emission allowances in the restricted permit market:

- AUCTION: Energy-intensive sectors must purchase all their emission rights at the international market price and do not receive any revenue rebate.

- OUTPUT: The emission entitlements set aside by the domestic government are allocated to the energy-intensive sectors according to the output-based rule.

- EMISSION: The emission entitlements set aside by the domestic government are allocated to the energy-intensive sectors according to the emission-based rule. 
Table 5 summarizes the main characteristics of the abatement scenarios under investigation.

Table 5: Overview of key scenarios

\begin{tabular}{|l|l|l|c|}
\hline Scenario & Regulation Scheme & OTHER & $\begin{array}{c}\text { International } \\
\text { Emissions } \\
\text { Trading }\end{array}$ \\
\hline EIS & $\mathrm{CO}_{2}$-Tax & $\mathrm{CO}_{2}$-Tax & No \\
\hline DOMESTIC & Permit Trade / output based rule & $\mathrm{CO}_{2}$-Tax & No \\
\hline TRD & Permit Trade / auctioned & Permit Trade / auctioned & Yes \\
\hline AUCTION & Permit / auctioned & $\mathrm{CO}_{2}$-Tax & Yes \\
\hline OUTPUT & Permit / emission based rule & $\mathrm{CO}_{2}$-Tax & Yes \\
\hline EMISSION & Permit / emission-based rule & $\mathrm{CO}_{2}$-Tax & Yes \\
\hline
\end{tabular}

\subsection{Results}

Simulation results are provided for the central case of Germany and an overall cutback requirement of $20 \%$ which roughly reflects the magnitude of Germany's greenhouse gas reduction target in the burden sharing agreement under the Kyoto Protocol (except that we use emissions in 1998 as reference point instead of 1990).

\subsubsection{Closed System}

Table 6 summarizes the results for the two scenarios that refer to a closed system without international trade of emission rights.

Table 6: Results for the closed trading system

\begin{tabular}{|c|c|c|}
\hline Item / Scenario & NTR & DOMESTIC \\
\hline Marginal abatement cost in $\$ \mathrm{US} / \mathrm{tC}$ & 68 & $\mathrm{ROE}^{*}: 70$ \\
\hline Consumption (percent change from baseline) & -0.22 & -0.29 \\
\hline Output in EIS (percent change from baseline) & -12.4 & -3.8 \\
\hline Employment in EIS (percent change from baseline) & -8.2 & -0.1 \\
\hline Output in ROI (percent change from baseline) & 0.6 & -0.2 \\
\hline Employment in ROI (percent change from baseline) & 1.1 & 0.1 \\
\hline
\end{tabular}

- Includes ROI and final demand 
Under $N T R$, a uniform carbon tax of $70 \mathrm{USD} / \mathrm{tC}$ must be levied to effect an emission cutback by $20 \%$. Imposition of the carbon tax induces adjustment of production and consumption patterns to substitute away from carbon (by fuel-switching and energy savings). For the NTR case, total adjustment costs - measured in terms of real consumption (income) amount to $0.22 \%$ of the aggregate benchmark consumption value. Carbon taxes increase the costs of production, particularly for the energy-intensive sectors in which energy represents a significant share of direct and indirect costs. This leads to a distinct decline in aggregate output and employment by $12.4 \%$ and $8.2 \%$ respectively.

Free allocation of emission allowances to energy-intensive sectors according to the output-based rule (scenario DOMESTIC) drastically ameliorate the adverse impacts on production and employment of these sectors: The decrease in aggregate EIS output only amounts to a third of the NTR value, while employment losses are negligible (due to additional substitution effects). Among EIS industries, production and employment gains relative to the NTR case are largest for the electricity sector which is most subsidized because of the highest carbon intensity. The benefits to employment and production in EIS goes at the expense of ROI since the relative consumer prices under DOMESTIC are distorted in favor of EIS.

The softening of structural change through the output subsidy to energy-intensive production generates non-negligible efficiency losses: Economy-wide adjustment costs increase by nearly a third from $0.22 \%$ to $0.29 \%$. Under pure efficiency considerations, the output subsidies to EIS trigger higher-than-optimal production of these sectors, which - in the closed system - requires a lower emission rate to comply with the exogenously fixed emission budget. The lower emission rate is reflected in the increased marginal abatement cost (123 \$US/tC), i.e. higher marginal cost of control, for the restricted permit system vis-à-vis the uniform carbon tax. To put it in a nutshell, the output-based rule shifts emission efforts towards more costly emission rate reductions and away from less costly output reduction.

\subsubsection{Open System}

Cost-effectiveness of carbon abatement policies suggests the implementation of emission reduction where it is cheapest. From an international perspective, this calls for an open system with unrestricted where-flexibility through policy instruments such as emissions trading or project-based bilateral abatement activities (such as Joint Implementation (JI) and the Clean Development Mechanism(CDM)). The recent climate policy process has effectively rendered comprehensive where-flexibility a conditio-sine-qua-non for the implementation of the Kyoto Protocol. It seems politically unfeasible that national governments could defend abatement policies within a closed system imposing potentially high excess costs to regulated domestic parties due to foregone gains from where-flexibility. 
Most policy-relevant are, therefore, the economic implications of allowance allocation schemes in an open system. For example, the EU directive on emissions trading between the EU's energy-intensive industries envisages a link with other (non-EU) trading schemes and project-based measures like JI and CDM under the Kyoto Protocol.

To visualize the sensitivity of economic effects with respect to the level of the international permit price, we revert to a graphical exposition of results where results are plotted as a function of the international permit price ranging from 10 \$US up to 300 \$US per ton of carbon.

We start the discussion of results with the policy-induced adjustment of aggregate production in energy-intensive industries. In Figure 4, we see that both distortionary allocation schemes (OUTPUT, EMISSION) avoid a stronger decline in EIS production because of the associated output subsidies.

Figure 4: Output effects for energy-intensive industries

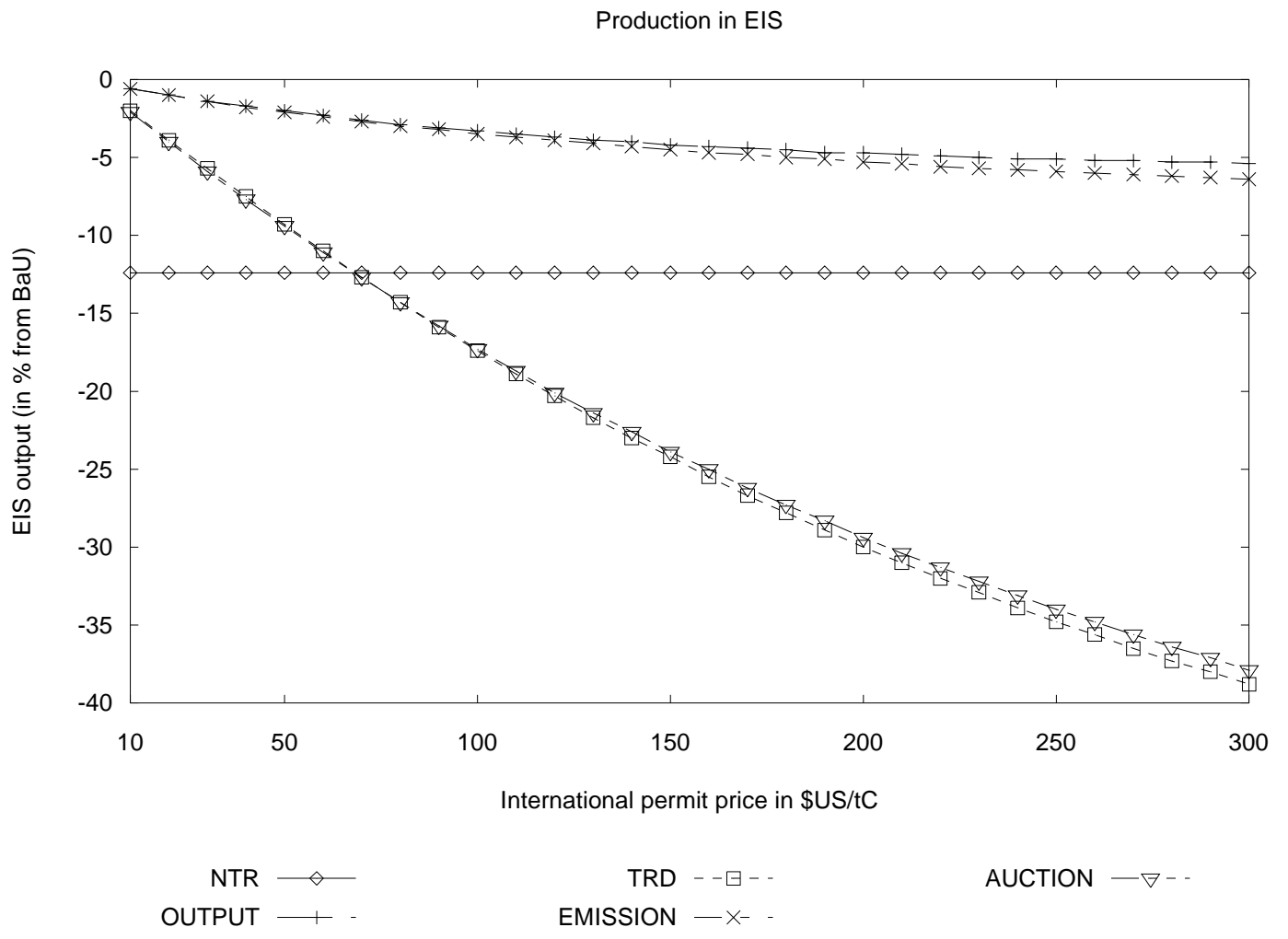

Compared to the efficient decline in EIS production under the AUCTION case for a restricted trading system or the comprehensive trading case (scenario TRD), the "optimal" production adjustment becomes dramatically distorted towards higher international permit prices under output- or emission-based allocation: From an efficiency point of view, it would be desirable to gradually cut back energy-intensive production towards higher permit prices 
in order to exploit gains from selling domestic emission allowance; the output subsidies, however, directly override this incentive.

Figure 5 illustrates the implications on emission rates of energy-intensive industries. The graph confirms the key mechanisms of the output- and emission-based rules as laid out in the partial equilibrium analysis of section 2 . The efficient emission rate declines rather strongly with the international permit price, reflecting the attractiveness of emission rate reduction to benefit either from reduced expenditures on import sales or higher revenues from permit exports. While the output-based rule warrants the socially efficient emission rate (there are only very small deviations due to general equilibrium feed-back effects), the emission rate under the emission-based rule is dramatically higher because of the additional input subsidization of emission use in EIS sectors.

Figure 5: Emission rates in energy-intensive sectors

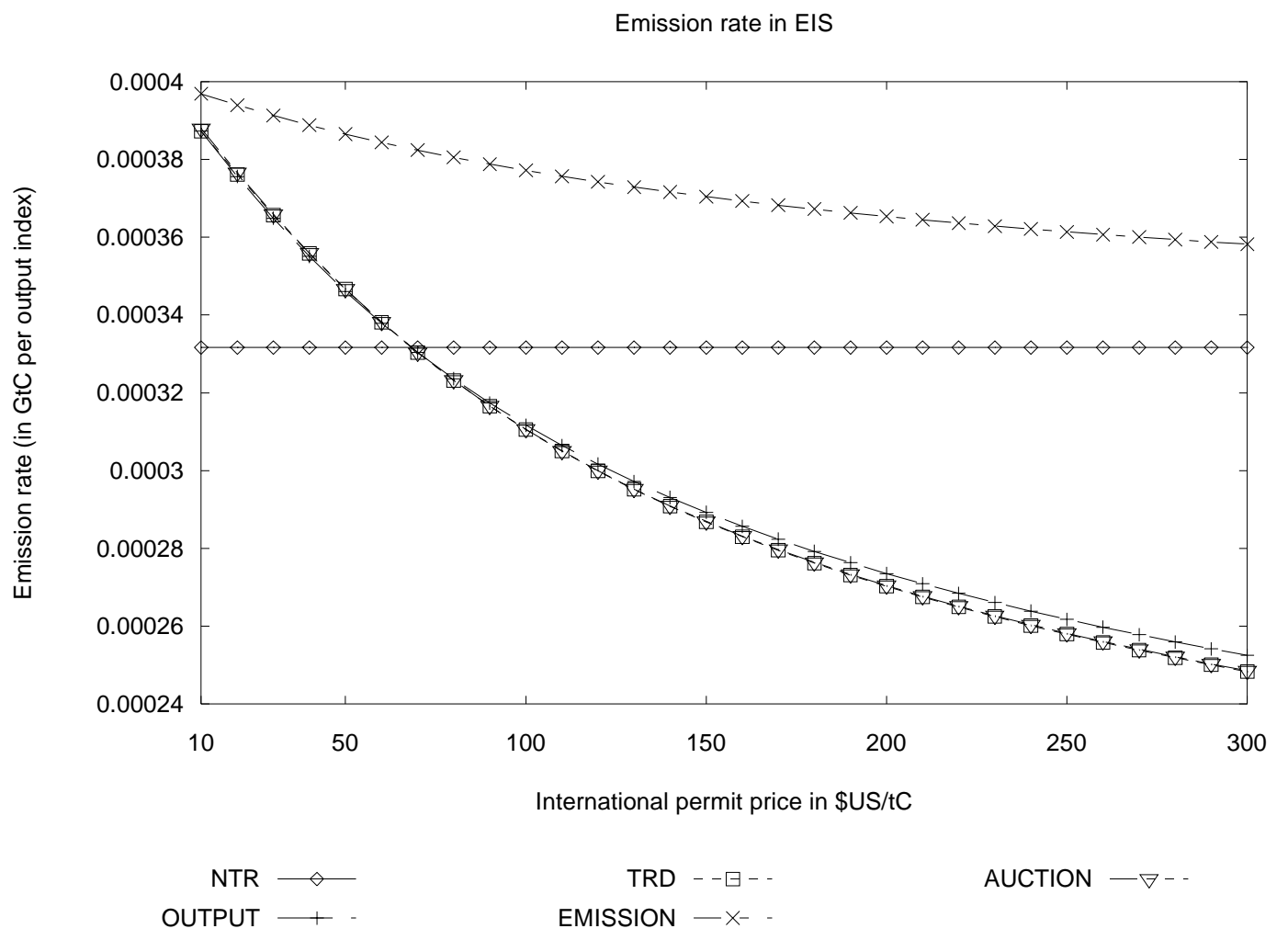

Based on Figures 4 and 5, the implications for emissions trading - depicted in Figure 6 - are straightforward. Across all scenarios, exports of emission permits increase towards higher international prices, which indicates the increased economic incentive of domestic emission abatement in energy-intensive industries eligible for carbon trade. However, the concrete trajectories for carbon trade are quite different. Compared to the scenarios $A U C T I O N$ and TRD where permits are auctioned, the import level of carbon is always too high - likewise, the level of exports is too low - under OUTPUT and EMISSION. 
Figure 6: Emission trade

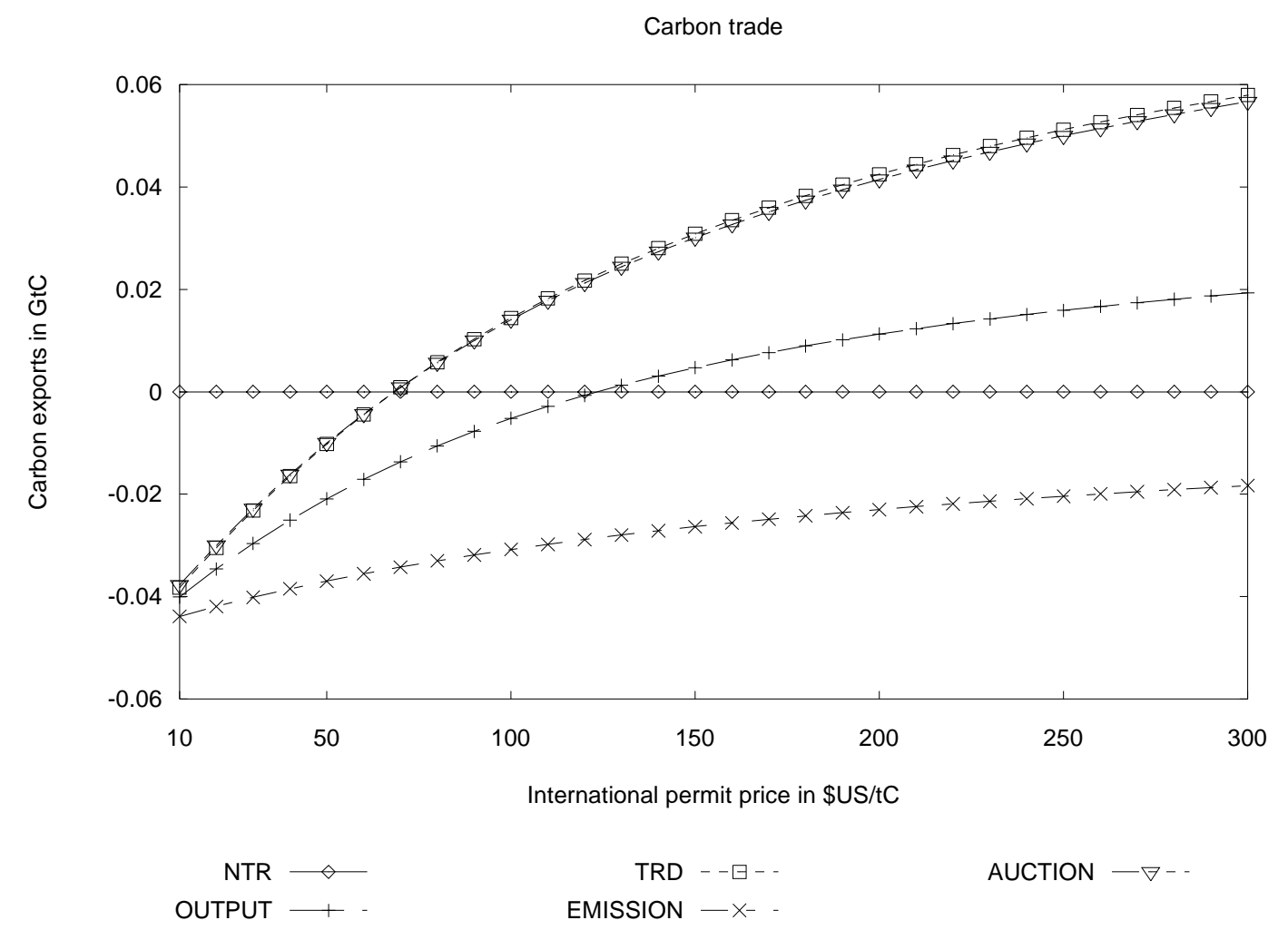

In general, the switch from importing permits to exporting permits takes place when the international permit price increases from below to above the autarky marginal abatement costs effectively perceived by the industries. This change in the trade position requires substantially higher international permit prices for the OUTPUT scenario because of subsidized domestic production. Under EMISSION, not only is the domestic production too high from an efficiency point of view, but the emission rate is too. As a consequence, the emission-based allocation scenario stands out for way too much domestic emissions vis-à-vis the efficient level. In fact, as has been laid out in the analytical exposition of sector 2, the emission-based allocation scheme implies a permanent carbon importing position where total domestic emissions of energy-intensive industries stay (asymptotically) above the total emission allowance. Clearly, this imposes very high excess costs towards increasing international permit prices because of larger foregone gains from permit trade.

The efficiency costs of distortionary allocation schemes are displayed in Figure 7. For the above reasoning, EMISSION is the sole scenario that exhibits steadily increasing adjustment costs in the international permit price. The shape of the TRD and AUCTION curves are straightforward from economic textbook intuition. The abating economy benefits from reduced adjustment costs vis-à-vis the NTR case whenever the international permit price differs from the autarky marginal abatement costs. 


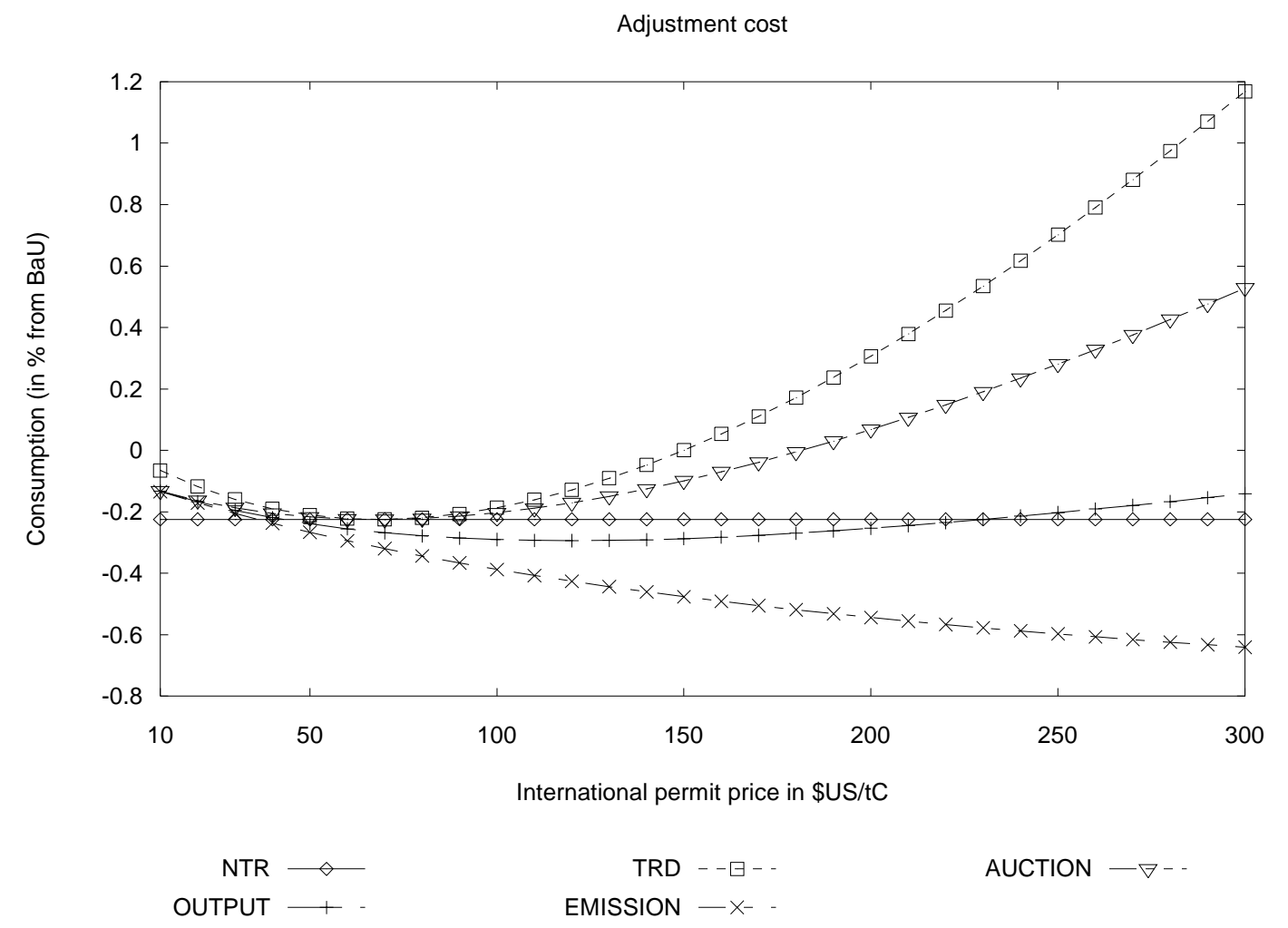

If the international permit price falls below the autarky marginal abatement cost, the economy is better off with imports that replace more costly domestic emission reduction. If the international permit price is above the autarky marginal abatement cost, the economy benefits from revenues of permit exports that exceed the costs of domestic abatement.

In qualitative terms, the scenario OUTPUT exhibits the same characteristics as $A U C T I O N$ or TRD; however, the induced welfare loss from output subsidization exceeds the gains from permit trade over a larger range of international permit prices.

Finally, we turn to the employment impacts that - in policy practice - might constitute the central trade-off with pure efficiency considerations. In Figure 8, we see that the distortionary allocation schemes $d o$ offset to a large extent the adverse employment impacts of emission constraints for the energy-intensive sectors. Yet, this compensation to the labor force in EIS sectors comes at increasing efficiency costs towards higher international permit prices, particularly for the case of emission-based allowance allocation.

When we cross-compare the two distortionary allocation schemes, the most important insight from our numerical analysis is that the output-based rule not only induces substantially lower efficiency losses than the emission-based rule but also performs better with respect to the compensating objectives in production and employment. The main reason is that real disposable income is higher under the less distortionary output-based rule. Thus, 
consumption demand for final goods, including EIS, is higher inducing higher production and employment levels.

Figure 8: Employment in energy-intensive industries

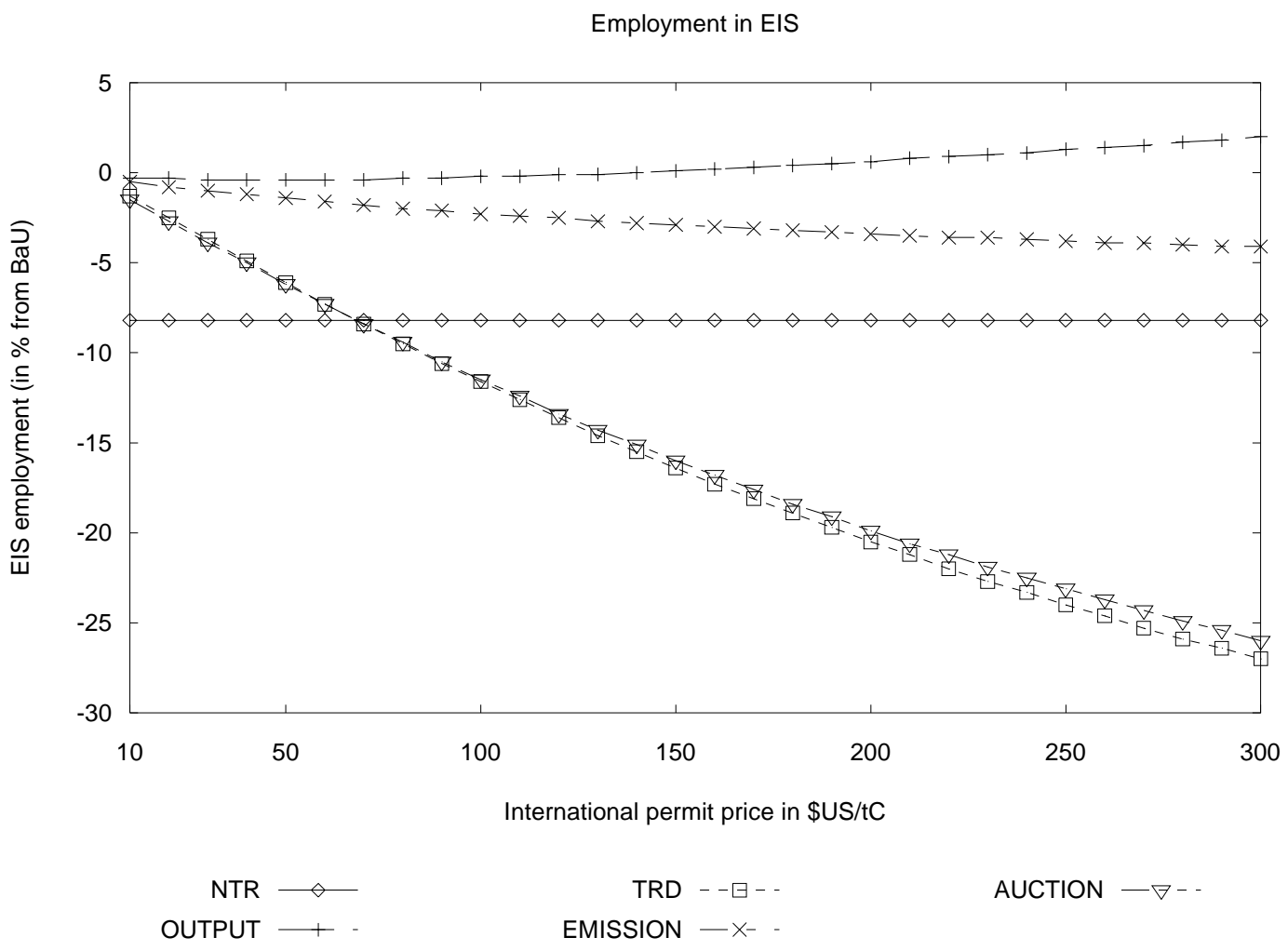

As to ROI, production and employment under TRD and AUCTION increase monotonically towards higher international permit prices because the cost advantage for nonenergy intensive production and services becomes more and more pronounced. If permits are freely allocated to EIS under EMISSION or OUTPUT, structural change towards ROI is substantially weakened; the production and employment "gap" for ROI between the efficient abatement policies (TRD and AUCTION) and the inefficient policies (EMISSION and OUTPUT) widens more and more towards higher international permit prices.

\section{Sensitivity Analysis}

To evaluate the sensitivity of our results we have run additional simulations for alternative assumptions on (i) the emission reduction target, (ii) benchmark data, and (iii) the international dimension of abatement policies. We find that all of our insights based on the central case simulations remain robust.

\subsection{Reduction Targets}

More stringent abatement targets increase the adjustment costs for all abatement scenarios, i.e. the curves displayed in Figure 7 move downwards (likewise upwards for 
relaxed targets). In the open trading system, the excess costs of both distortionary allocation rules, however, decrease towards higher reduction targets. The reason is that the total amount of emission allowances being freely allocated to energy-intensive industries declines and, thus, reduces the effective subsidy. Figure 9 illustrates the efficiency differences between OUTPUT and EMISSION for alternative targets ranging from $5 \%$ to $30 \%$ emission reduction vis-à-vis the benchmark emission level. Likewise, EIS output and employment gains of the output-based rule compared to the emission-based rule decrease towards higher reduction targets, i.e. smaller amounts of freely allocated permits.

Figure 9: Efficiency gap between OUTPUT and EMISSION

Efficiency advantage of OUTPUT over EMISSION

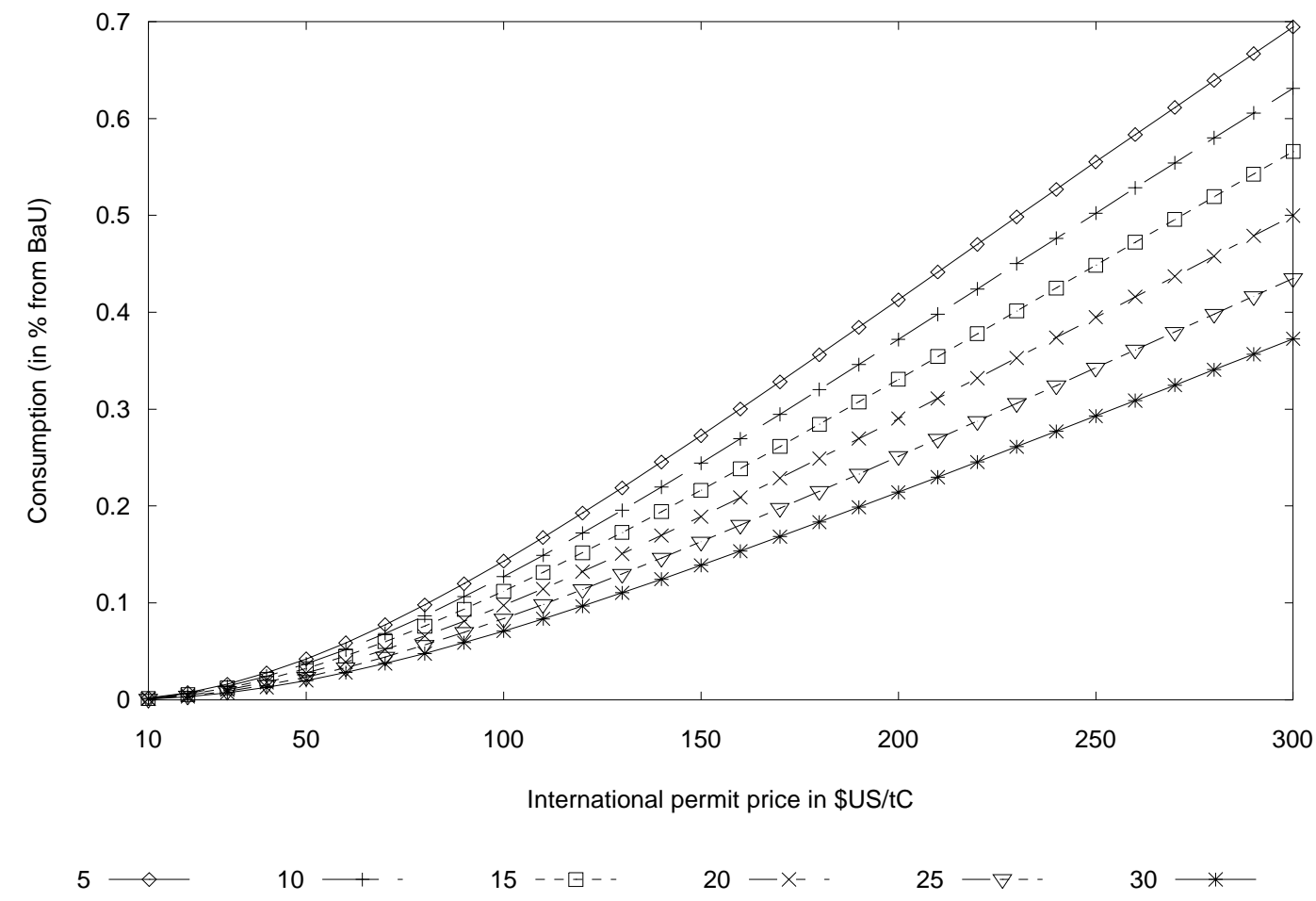

It should be noted that in the closed system with endogenous allowance prices the tightening of reduction targets produces two effects working in opposite directions. On the one hand, the shadow price of carbon emissions will increase, hereby augmenting the implicit subsidy to energy-intensive industries; on the other hand, the decline in freely allocated emission allowances will decrease the subsidy: Figure B.1 in Appendix B visualizes the aggregate impact on adjustment costs and EIS employment for the German economy: Towards higher reduction targets the excess costs of the output-based rule (scenario DOMESTIC) increase vis-à-vis the NTR scenario while the relative employment losses decrease. 


\subsection{Benchmark Data}

In order to investigate the robustness of results with respect to the underlying benchmark data, we have conducted simulations based for a number of industrialized countries. Figures B.2.1-B.2.6 in Appendix B visualize the results for the U.S., Japan, Great Britain, France, Spain, and Italy reflecting a $20 \%$ emission cutback compared to the respective benchmark emission level. All of our insights from the core simulation remain robust.

\subsection{Multilateral Abatement}

In our core simulations, we have considered unilateral abatement policies by a small open economy. To gain insights how equivalent abatement policies by major trading partners affect our results, we have set-up a 2-region model variant with bilateral trade where both regions (here: Germany and the remaining aggregate of EU-15) undertake identical abatement policies. As illustrated by Figures 10 and 11, endogenisation of terms-of-trade for multilateral abatement policies produces only second-order effects that do not change the findings from the small open economy setting.

Figure 10: Adjustment costs for the German economy for multilateral abatement policies

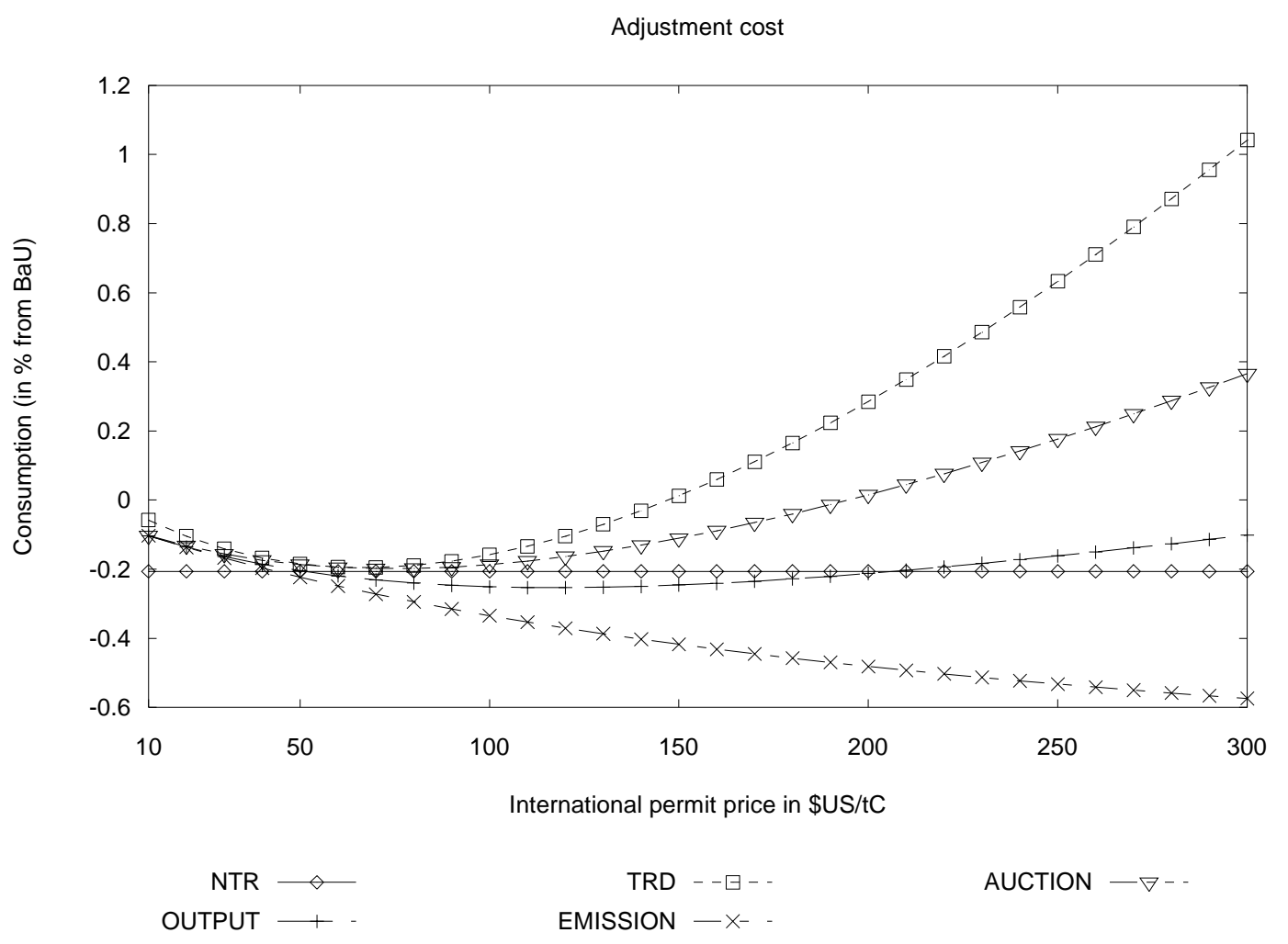


Figure 11: Employment in energy-intensive German industries for multilateral abatement policies

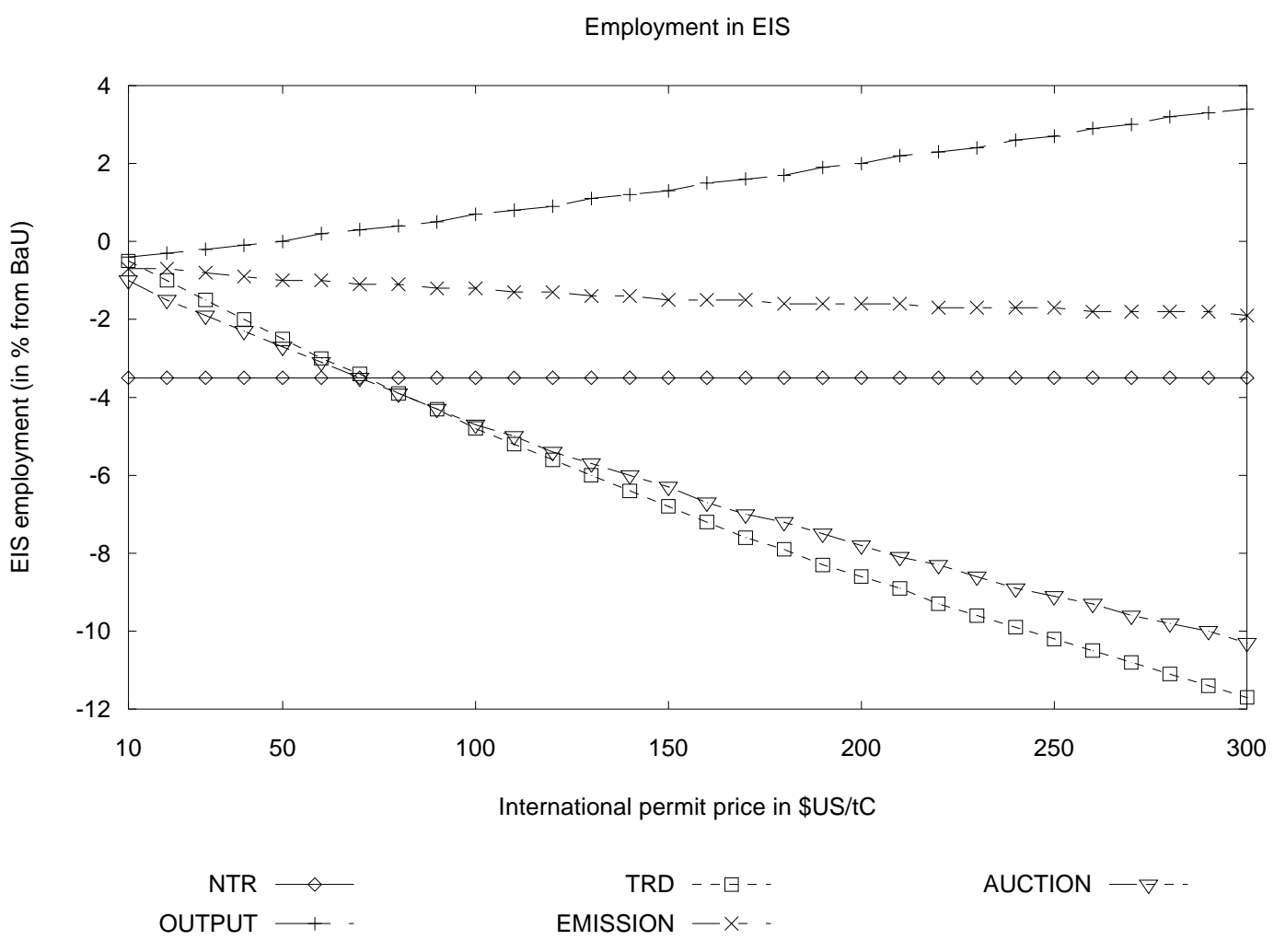

\section{Conclusions}

Environmental regulation schemes often entail some type of compensation to reduce the specific costs for regulated industries. Since compensating mechanisms typically aim at the reduction of adverse production and employment effects in these industries, there is an inherent trade-off for environmental policy between the issue of efficiency and compensation.

We have analyzed this trade-off for tradable permit systems with free initial allocation of emission allowances based on either emissions or output. Combining theoretical partial equilibrium analysis with numerical general equilibrium analysis, we find that the trade-off between efficiency and compensation in open trading systems crucially depends on the level of the international permit price. The efficiency costs for ameliorating adverse production and output effects in energy-intensive industries through output-based or emission-based allocation becomes more costly, the higher the international permit price is. The costs reflect foregone gains from permit trading because of permit imports that are too high or, likewise, permit exports that are too small compared to the efficient volumes under auctioned permit systems.

In the open trading system, the output-based allocation rule is distinctly less costly than the emission-based rule to preserve output and employment in energy-intensive sectors. 
Emission-based allocation is particularly expensive towards higher international permit prices where the implicit subsidies for emission use in energy-intensive sectors produce drastic efficiency losses since they imply high expenditures for carbon permit imports rather than high net revenues from efficient carbon permit exports. Only for small international permit prices is there a relatively small gap in cost-effectiveness (i.e. efficiency costs for reduced production or employment frictions) between the output- and emission-based rule.

This leads us to our final policy conclusions with respect to the current discussion of emissions trading schemes under the Kyoto Protocol. The international permit price of a broader emission trading system is likely to be very small after accounting for U.S. withdrawal and large amounts of hot air by the Former Soviet Union. Therefore, the efficiency costs of an output-based allocation can be expected to be relatively small for the Kyoto commitment period, while the political economy benefits with respect to political acceptance might be rather large. Thus, our analysis confirms the broader rationale for an output-based free (initial) allocation of emission allowances. However, we also clearly show that the costs of compensation can increase substantially in future commitment periods where emission reduction constraints and implied emission permit prices are likely to be much higher. In designing a longer-term trading scheme, policy makers should therefore credibly announce transition to non-distortionary auctioning of emission allowances.

There are various potentially important aspects missing from our investigation. Climate policy in OECD countries is not a green field. Several initiatives to reduce anthropogenic carbon emissions ranging from command-and-control (such as insulation standards) and voluntary agreements to tax instruments (such as energy taxes) co-exist. The design of (restricted) trading schemes must account for pre-existing regulation to avoid inefficiencies and multiple regulation of economic agents. Furthermore, the free choice of alternative allocation schemes across regions can create strong incentives for strategic environmental policy. For example, EU member countries under the EU Directive can determine the amount of emission rights and the specific allocation rules to energy-intensive industries in order to improve competitiveness of domestic influential branches. We plan to address these issues in future research.

\section{References}

Armington, P.S. (1969), A Theory of Demand for Producers Distinguished by Place of Production, IMF Staff Papers 16, 159-178.

Böhringer, C., M. Ferris, and T.F. Rutherford (1998), Alternative $\mathrm{CO}_{2}$ abatement strategies for the European Union, in: J. Braden and S. Proost (eds.), Climate Change, Transport and Environmental Policy, Edward Elgar, Cheltenham, 16-47. 
Böhringer, C. and C. Vogt (2003), Economic and Environmental Impacts of the Kyoto Protocol, Canadian Journal of Economics, 36(2), 475-494.

Böhringer, C. and A. Lange (2003), On the Design of Optimal Grandfathering Schemes for Emission Allowances, Discussion Paper 03-08, ZEW (Centre for European Economic Research), Mannheim.

Burtraw, D. (1999), Cost Savings, Market Performance and Economic Benefits of the U.S. Acid Rain Program, in: Sorell, S. and Skea, J. (eds.), Tradeable Permits, Tradeable Quotas and Joint Implementation, Edward Elgar, Cheltenham.

EU (2001), Proposal for a framework Directive for greenhouse gas emissions trading within the European Community, COM (2001)581, European Commission, Brussels (http://europa.eu.int/eur-lex/fr/com/pdf/2001/fr_501PC0581.pdf).

Fisher, C. (2001), Rebating Environmental Policy Revenues: Output-Based Allocations and Tradable Performance Standards, Discussion Paper 01-22, Resources for the Future, Washington.

Goulder, L. H. (1995), Environmental Taxation and the Double Dividend: A Readers' Guide, International Tax and Public Finance 2, 157-183.

Goulder, L.H., I.W.H. Parry, and D. B. Burtraw (1999), When can Carbon Abatement Policies Increase Welfare? The Fundamental Role of Distorted Factor Markets, Journal of Environmental Economics and Management, 37, 52-84.

Jensen, J. and T. N. Rasmussen (2000), Allocation of CO2 Emission Permits: A General Equilibrium Analysis of Policy Instruments, Journal of Environmental Economics and Management 40, 111-136.

McDougall, R.A. (1999), ed., Global Trade, Assistance and Protection: The GTAP 5 Data Base, Center for Global Trade Analysis, Purdue University, West Lafayette.

OECD (2001), Database on environmentally related taxes in OECD countries. Available at: http://www.oecd.org/env/policies.

Stavins, R.N. (1998), What Can We Learn from the Grand Policy Experiment? Lessons from SO2 Allowance Trading, Journal of Economic Perspectives, 12(3), 69-88. 


\section{Appendix A: Algebraic Model Summary}

This appendix provides an algebraic summary of the equilibrium conditions for our comparative-static model designed to investigate the economic implications of alternative allowance allocation rules. For the generic model the following assumptions apply:

- Nested separable constant elasticity of substitution (CES) functions characterize the use of inputs in production. All production exhibits non-increasing returns to scale. Goods are produced with capital, labor, energy and material (KLEM).

- A representative agent (RA) in each region is endowed with three primary factors: natural resources (used for fossil fuel production), labor and capital. The RA maximizes utility from consumption of a CES composite subject to a budget constraint with fixed investment demand (i.e. fixed demand for the savings good). The aggregate consumption bundle combines demands for fossil fuels, electricity and non-energy commodities. Total income of the RA consists of factor income and taxes (including revenues from carbon taxes or auctioned carbon permits).

- Supplies of labor, capital and fossil-fuel resources are exogenous. Labor and capital are mobile within domestic borders but cannot move between regions; natural resources are sector specific.

- All goods are differentiated by region of origin. Constant elasticity of transformation functions (CET) characterize the differentiation of production between production for the domestic markets and the export markets. Regarding imports, nested CES functions characterize the choice between imported and domestic varieties of the same good (Armington).

- Goods from regions which are not explicitly represented (rest of the world - ROW) are differentiated, and a set of horizontal export demand and import supply functions determine the trade between ROW and the regions whose production and consumption patterns are described in detail. In other words, the representation of ROW is reduced to import and export flows with the explicit regions of the model where the latter are assumed to be price-takers with respect to ROW import and export prices.

The model is formulated as a system of nonlinear inequalities. These inequalities correspond to two classes of equilibrium conditions: zero profit and market clearance. The fundamental unknowns of the system are two vectors: activity levels and prices. In equilibrium, each of these variables is linked to one inequality condition: an activity level to a zero-profit condition and a commodity (factor) price to a market-clearance condition.

In the algebraic exposition below, the notation $\Pi_{i r}^{z}$ is used to denote the (zero-)profit function of sector $j$ in region $r$ where $z$ is the name assigned to the associated production 
activity. Differentiating the profit function with respect to input and output prices provides compensated demand and supply coefficients (Hotellings's lemma), which appear subsequently in the market clearance conditions. We use $i$ (aliased with $j$ ) as an index for commodities (sectors) and $r$ (aliased with $s$ ) as an index for regions. The label $E G$ represents the set of energy goods and the label $F F$ denotes the subset of fossil fuels. Tables A.1 - A.6 explain the notations for variables and parameters employed within our algebraic exposition. Figures A.1 - A.5 provide a graphical exposition of the production and final consumption structure.

\section{A.1 Zero Profit Conditions}

1. Production of goods except fossil fuels:

$$
\begin{aligned}
\prod_{i r}^{Y}= & \left(\theta_{i r}^{X R O W} p^{W^{1-\eta}}+\left(1-\theta_{i r}^{X}\right) p_{i r}^{1-\eta}\right)^{\frac{1}{1-\eta}}-\sum_{j \notin E G} \theta_{j i r} p_{j r}^{A} \\
& -\theta_{i r}^{K L E}\left[\theta_{i r}^{E} p_{i r}^{E 1-\sigma_{K L E}}+\left(1-\theta_{i r}^{E}\right)\left(w_{r}^{\alpha_{j r}^{L}} v_{r}^{\alpha_{j r}^{K}}\right)^{1-\sigma_{K L E}}\right]^{\frac{1}{1-\sigma_{K L E}}} \leq 0 \quad \mathrm{i} \notin \mathrm{FF}
\end{aligned}
$$

where $Y_{i r}(i \notin f f)$ is the associated activity variable.

2. Production of fossil fuels:

$$
\begin{aligned}
\Pi_{i r}^{Y}= & \left(\theta_{i r}^{X R O W} p^{W^{1-\eta}}+\left(1-\theta_{i r}^{X}\right) p_{i r}^{1-\eta}\right)^{\frac{1}{1-\eta}} \\
& -\left[\theta_{i r}^{Q} q_{i r}^{1-\sigma_{Q, i}}+\left(1-\theta_{i r}^{Q}\right)\left(\theta_{L i r}^{F F} w_{r}+\theta_{K i r}^{F F} v_{r}+\sum_{j} \theta_{j i r}^{F F} p_{j r}^{A}\right)^{1-\sigma_{Q, i}}\right]^{\frac{1}{1-\sigma_{Q, i}}} \leq 0 \quad \mathrm{i} \in \mathrm{FF}
\end{aligned}
$$

where $Y_{i r}(i \in f f)$ is the associated activity variable.

3. Sector-specific energy aggregate:

$$
\prod_{i r}^{E}=p_{i r}^{E}-\left\{\theta_{i r}^{E L E} p_{\{E L E, r\}}^{A^{1-\sigma_{E L E}}}+\left(1-\theta_{i r}^{E L E}\right)\left[\theta_{i r}^{C O A} p_{\{C O A, r\}}^{A^{1-\sigma} C O A}+\left(1-\theta_{i r}^{C O A}\right)\left(\prod_{j \in L Q} p_{j r}^{A^{\beta_{j i r}}}\right)^{1-\sigma_{C O A}}\right]^{\frac{1-\sigma_{E L E}}{1-\sigma_{C O A}}}\right\}^{\frac{1}{1-\sigma_{E L E}}} \leq 0
$$

where $E_{i r}$ is the associated activity variable.

4. Armington aggregate:

$$
\prod_{i r}^{A}=p_{i r}^{A}-\left[\left(\theta_{i r}^{A} p_{i r}^{1-\sigma_{A}}+\left(1-\theta_{i r}^{A}\right) p_{i r}^{M^{1 \cdot \sigma_{A}}}\right)^{\frac{1}{1-\sigma_{A}}}+p_{r}^{C O 2} a_{i}^{C O 2}\right] \leq 0
$$

where $A_{i r}$ is the associated activity variable. 
5. Aggregate imports across import regions:

$$
\prod_{i r}^{M}=p_{i r}^{M}-\left(\sum_{s} \theta_{i s r}^{M} p_{i s}^{X^{l-\sigma_{M}}}+\theta_{i r}^{M R O W} p^{W^{l-\sigma_{M}}}\right)^{\frac{1}{1-\sigma_{M}}} \leq 0
$$

where $M_{i r}$ is the associated activity variable.

6. Household consumption aggregate:

$$
\left.\prod_{r}^{C}=p_{r}^{C}-\left(\theta_{C r}^{E} p_{C r}^{E}{ }^{l-\sigma_{E C}}+\left(1-\theta_{C r}^{E}\right)\left[\prod_{i \notin F F} p_{i r}^{A^{\gamma_{i r}}}\right)\right]^{I-\sigma_{E C}}\right)^{\frac{1}{1-\sigma_{E C}}} \leq 0
$$

where $C_{r}$ is the associated activity variable.

7. Household energy aggregate:

$$
\prod_{C r}^{E}=p_{C r}^{E}-\left[\sum_{i \in F F} \theta_{i C r}^{E} p_{i r}^{A}{ }^{1-\sigma_{F F, C}}\right]^{\frac{1}{1-\sigma_{F F, C}}} \leq 0
$$

where $E_{C r}$ is the associated activity variable.

8. Investment:

$$
\prod_{r}^{I}=p_{r}^{I}-\sum_{i} \theta_{i r}^{I} p_{i r}^{A} \leq 0
$$

where $I_{r}$ is the associated activity variable.

\section{A.2}

\section{Market Clearance Conditions}

9. Labor:

$$
\bar{L}_{r} \geq \sum_{i} Y_{i r} \frac{\partial \prod_{i r}^{Y}}{\partial w_{r}}
$$

where $w_{r}$ is the associated price variable.

10. Capital:

$$
\bar{K}_{r} \geq \sum_{i} Y_{i r} \frac{\partial \prod_{i r}^{Y}}{\partial v_{r}}
$$

where $v_{r}$ is the associated price variable. 
11. Natural resources:

$$
\bar{Q}_{i r}=Y_{i r} \frac{\partial \prod_{i r}^{Y}}{\partial q_{i r}} \quad i \in F F
$$

where $q_{i r}$ is the associated price variable.

12. Output for internal markets:

$$
Y_{i r} \frac{\partial \prod_{i r}^{Y}}{\partial p_{i r}} \geq A_{i r} \frac{\partial \prod_{i r}^{A}}{\partial p_{i r}}+\sum_{s \neq r} M_{i s} \frac{\partial \prod_{i s}^{M}}{\partial p_{i r}}
$$

where $p_{i r}$ is the associated price variable.

13. Sector-specific energy aggregate:

$$
E_{i r} \geq Y_{i r} \frac{\partial \prod_{i r}^{Y}}{\partial p_{i r}^{E}}
$$

where $p_{i r}^{E}$ is the associated price variable.

14. Import aggregate:

$$
M_{i r} \geq A_{i r} \frac{\partial \prod_{i r}^{A}}{\partial p_{i r}^{M}}
$$

where $p_{i r}^{M}$ is the associated price variable.

15. Armington aggregate:

$$
A_{i r} \geq \sum_{j} Y_{j r} \frac{\partial \prod_{j r}^{Y}}{\partial p_{i r}^{A}}+C_{r} \frac{\partial \prod_{r}^{C}}{\partial p_{i r}^{A}}+I_{r} \frac{\partial \Pi_{r}^{I}}{\partial p_{i r}^{A}}
$$

where $p_{i r}^{A}$ is the associated price variable.

16. Investment aggregate:

$$
\bar{I}_{r} \geq I_{r}
$$

where $p_{r}^{I}$ is the associated price variable.

17. Household consumption:

$$
C_{r} p_{r}^{C}=w_{r} \bar{L}_{r}+v_{r} \bar{K}_{r}+\sum_{j \in F F} q_{j r} \bar{Q}_{j r}+p_{r}^{C O 2} \overline{C O 2}_{r}+p_{r}^{I} \bar{I}_{r}+\bar{B}_{r}
$$

where $p_{r}^{C}$ is the associated price variable. 
18. Aggregate household energy consumption:

$$
E_{C r}=C_{r} \frac{\partial \Pi_{r}^{C}}{\partial p_{C r}^{E}}
$$

where $p_{C r}^{E}$ is the associated price variable.

19. Carbon emissions:

$$
\overline{C O 2}_{r}=\sum_{i} A_{i r} a_{i}^{C O 2}
$$

where $p_{r}^{\mathrm{CO} 2}$ is the associated price variable.

20. Balance of payments:

$$
\sum_{i, r} Y_{i r} \frac{\partial \prod_{i r}^{Y}}{\partial p^{W}}+\sum_{r} \bar{B}_{r}=\sum_{i, r} M_{i r} \frac{\partial \Pi_{i r}^{M}}{\partial p^{W}}
$$

where $p^{W}$ is the associated price variable.

Table A.1: $\quad$ Sets

\begin{tabular}{ll}
\hline $\mathrm{i}$ & Sectors and goods \\
$\mathrm{j}$ & Aliased with $\mathrm{i}$ \\
$\mathrm{r}$ & Regions \\
$\mathrm{s}$ & Aliased with $\mathrm{r}$ \\
$\mathrm{EG}$ & All energy goods: Coal, crude oil, refined oil, gas and electricity \\
FF & Primary fossil fuels: Coal, crude oil and gas \\
LQ & Liquid fuels: Crude oil and gas \\
\hline
\end{tabular}

Table A.2: Activity variables

\begin{tabular}{ll}
\hline$Y_{i r}$ & Production in sector $i$ and region $r$ \\
$E_{i r}$ & Aggregate energy input in sector $i$ and region $r$ \\
$M_{i r}$ & Aggregate imports of good $i$ and region $r$ \\
$A_{i r}$ & Armington aggregate of good $i$ in region $r$ \\
$C_{r}$ & Aggregate household consumption in region $r$ \\
$E_{C r}$ & Aggregate household energy consumption in region $r$ \\
$I_{r}$ & Aggregate investment in region $r$ \\
\hline
\end{tabular}


Table A.3: $\quad$ Price variables

\begin{tabular}{cl}
\hline$p_{i r}$ & Output price of good $i$ produced in region $r$ for domestic market \\
$p^{W}$ & Real exchange rate with the rest of the world (ROW) \\
$p_{i r}^{E}$ & Price of aggregate energy in sector $i$ and region $r$ \\
$p_{i r}^{M}$ & Import price aggregate for good $i$ imported to region $r$ \\
$p_{i r}^{A}$ & Price of Armington good $i$ in region $r$ \\
$p_{r}^{C}$ & Price of aggregate household consumption in region $r$ \\
$p_{C r}^{E}$ & Price of aggregate household energy consumption in region $r$ \\
$p_{r}^{I}$ & Price of aggregate investment good in region $r$ \\
$w_{r}$ & Wage rate in region $r$ \\
$v_{r}$ & Price of capital services in region $r$ \\
$q_{i r}$ & Rent to natural resources in region $r$ (i FF) \\
$p_{r}^{C O 2}$ & Shadow price of CO $\mathrm{CO}_{2}$ unit in region $r$ \\
\hline
\end{tabular}

Table A.4: Cost shares

\begin{tabular}{|c|c|}
\hline$\theta_{i r}^{\text {XROW }}$ & Share of ROW exports in sector $i$ and region $r$ \\
\hline$\theta_{j i r}$ & Share of intermediate good $j$ in sector $i$ and region $r(\mathrm{i} \notin \mathrm{FF})$ \\
\hline$\theta_{i r}^{K L E}$ & Share of KLE aggregate in sector $i$ and region $r(\mathrm{i} \notin \mathrm{FF})$ \\
\hline$\theta_{i r}^{E}$ & Share of energy in the KLE aggregate of sector $i$ and region $r(\mathrm{i} \notin \mathrm{FF})$ \\
\hline$\alpha_{i r}^{T}$ & Share of labor $(T=L)$ or capital $(T=K)$ in sector $i$ and region $r(\mathrm{i} \notin \mathrm{FF})$ \\
\hline$\theta_{i r}^{Q}$ & Share of natural resources in sector $i$ of region $r(\mathrm{i} \in \mathrm{FF})$ \\
\hline$\theta_{T i r}^{F F}$ & $\begin{array}{l}\text { Share of good } i(T=i) \text { or labor }(T=L) \text { or capital }(T=K) \text { in sector } i \text { and } \\
\text { region } r(\mathrm{i} \in \mathrm{FF})\end{array}$ \\
\hline$\theta_{i r}^{C O A}$ & Share of coal in fossil fuel demand by sector $i$ in region $r(\mathrm{i} \notin \mathrm{FF})$ \\
\hline$\theta_{i r}^{E L E}$ & Share of electricity in energy demand by sector $i$ in region $r$ \\
\hline$\beta_{j i r}$ & $\begin{array}{l}\text { Share of liquid fossil fuel } j \text { in energy demand by sector } i \text { in region } r \\
(\mathrm{i} \notin \mathrm{FF}, \mathrm{j} \in \mathrm{LQ})\end{array}$ \\
\hline$\theta_{i s r}^{M}$ & Share of imports of good $i$ from region $s$ to region $r$ \\
\hline$\theta_{i r}^{M R O W}$ & Share of ROW imports of good $i$ in region $r$ \\
\hline$\theta_{i r}^{A}$ & Share of domestic variety in Armington good $i$ of region $r$ \\
\hline
\end{tabular}




$\begin{array}{ll}\theta_{C r}^{E} & \begin{array}{l}\text { Share of fossil fuel composite in aggregate household consumption in } \\ \text { region } r\end{array} \\ \theta_{i r}^{I} & \begin{array}{l}\text { Share of good i in investment composite in region } r \\ \gamma_{i r}\end{array} \\ \theta_{i C r}^{E} & \begin{array}{l}\text { Share of non-energy good } i \text { in non-energy household consumption } \\ \text { demand in region } r\end{array} \\ & \text { Share of fossil fuel } i \text { in household energy consumption in region } r\end{array}$

Table A.5: $\quad$ Endowments and emissions coefficients

$\begin{array}{ll}\bar{L}_{r} & \text { Aggregate labor endowment for region } r \\ \bar{K}_{r} & \text { Aggregate capital endowment for region } r \\ \bar{Q}_{i r} & \text { Endowment of natural resource } i \text { for region } r(\mathrm{i} \in \mathrm{FF}) \\ \bar{B}_{r} & \left.\text { Balance of payment deficit or surplus in region r (note: } \sum_{r} \bar{B}_{r}=0\right) \\ \overline{C O_{2}} & \text { Endowment of carbon emission rights in region } r \\ a_{i}^{\mathrm{CO}_{2}} & \text { Carbon emissions coefficient for fossil fuel } i(i \in F F)\end{array}$

Table A.6: $\quad$ Elasticities

$\eta \quad$ Transformation between production for the domestic market 2 and production for the export

$\begin{array}{lll}\sigma_{K L E} & \text { Substitution between energy and value-added in production } & 0.8\end{array}$ (except fossil fuels)

$\begin{array}{ll}\sigma_{Q, i} & \text { Substitution between natural resources and other inputs in } \\ \text { fossil fuel production calibrated consistently to exogenous }\end{array}$ supply elasticities $\mu_{F F}$.

$\mu_{\mathrm{COA}}=0.5$

$\mu_{\mathrm{CRU}}=1.0$

$\mu_{\mathrm{GAS}}=1.0$

$\sigma_{E L E} \quad$ Substitution between electricity and the fossil fuel aggregate in $\quad 0.3$ production

$\sigma_{C O A} \quad$ Substitution between coal and the liquid fossil fuel composite $\quad 0.5$ in production

$\sigma_{A} \quad$ Substitution between the import aggregate and the domestic 4 input

$\begin{array}{lll}\sigma_{M} & \text { Substitution between imports from different regions } & 8\end{array}$

$\begin{array}{lll}\sigma_{E C} & \text { Substitution between the fossil fuel composite and the non- } 0.8\end{array}$ fossil fuel consumption aggregate in household consumption

$\sigma_{F F, C} \quad$ Substitution between fossil fuels in household fossil energy 0.3 consumption 
Figure A.1: Nesting in non-fossil fuel production

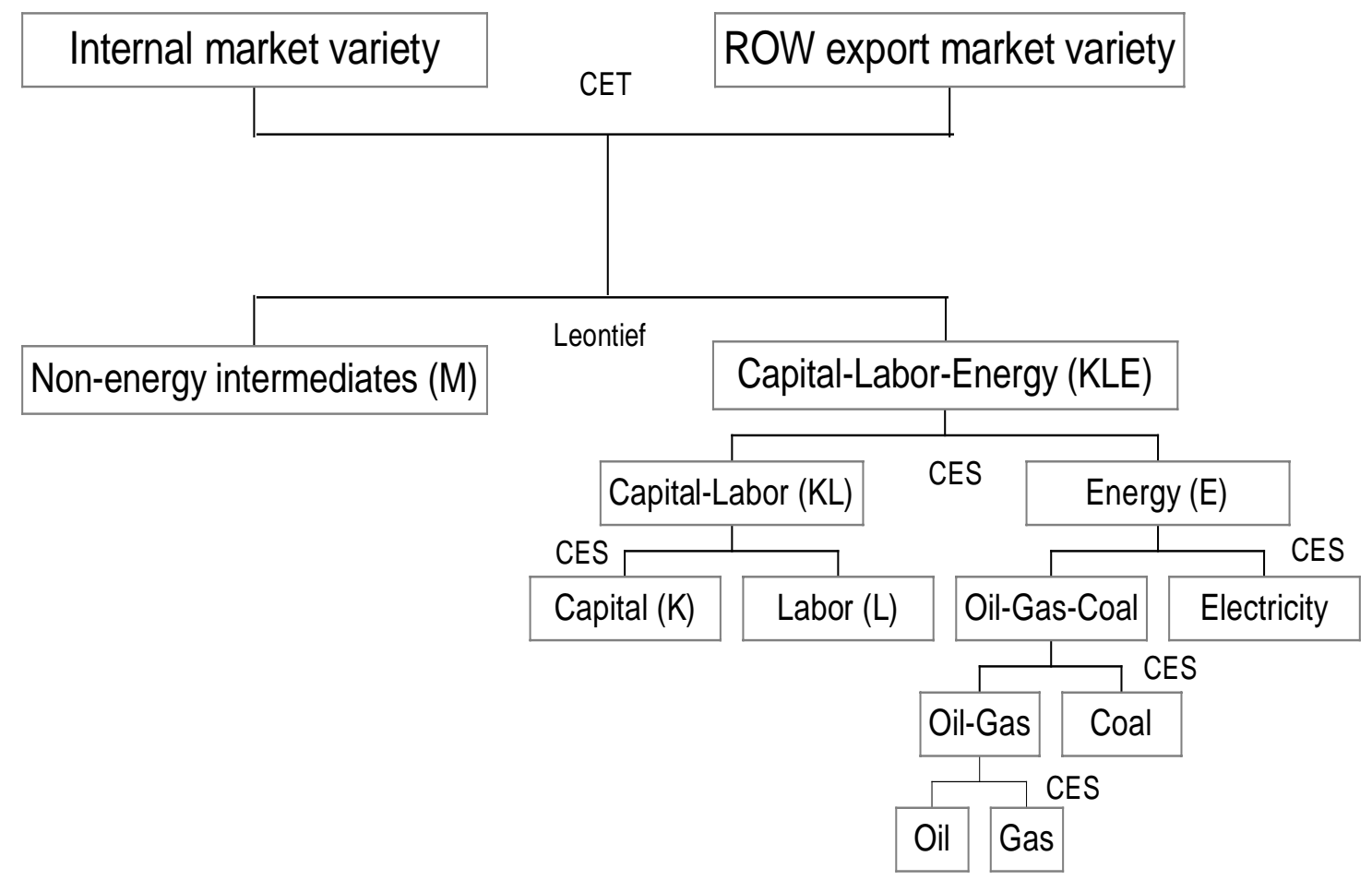

Figure A.2: Nesting in fossil fuel production

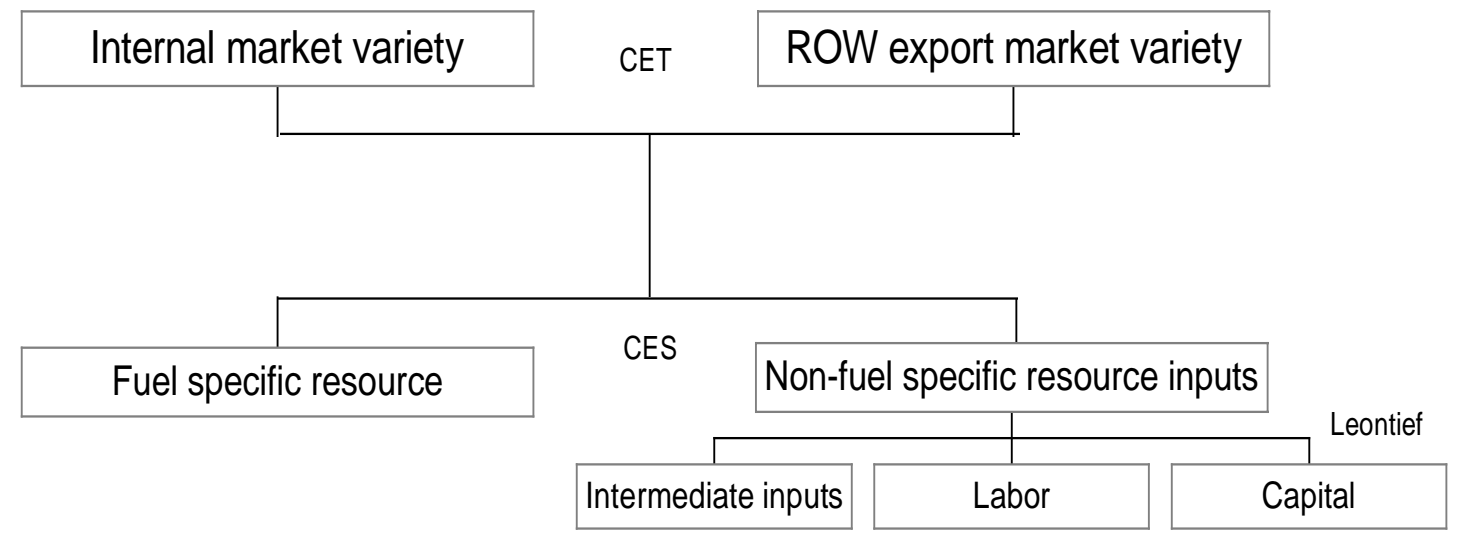

Figure A.3: Nesting in household consumption

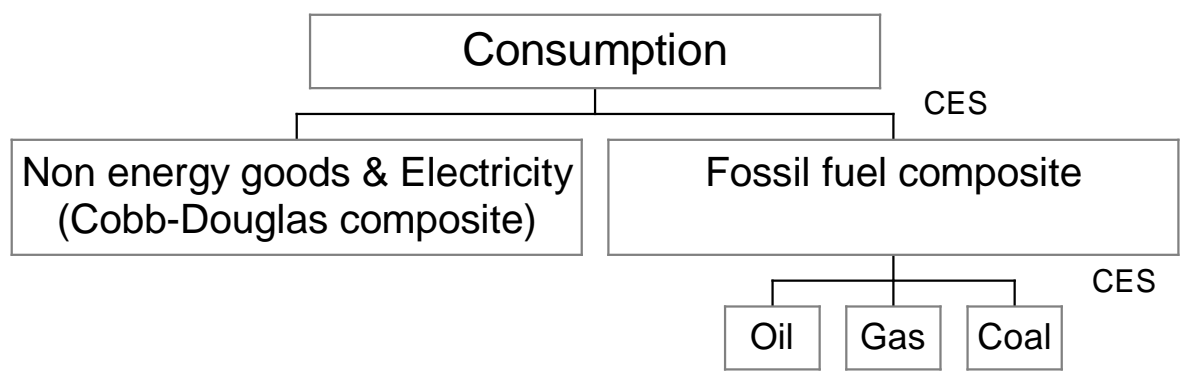


Figure A.4: Nesting in Armington production

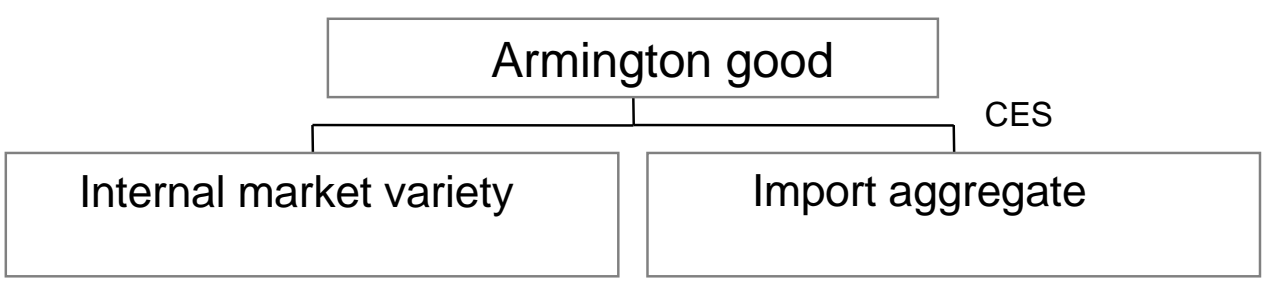

Figure A.5: Nesting in import aggregate

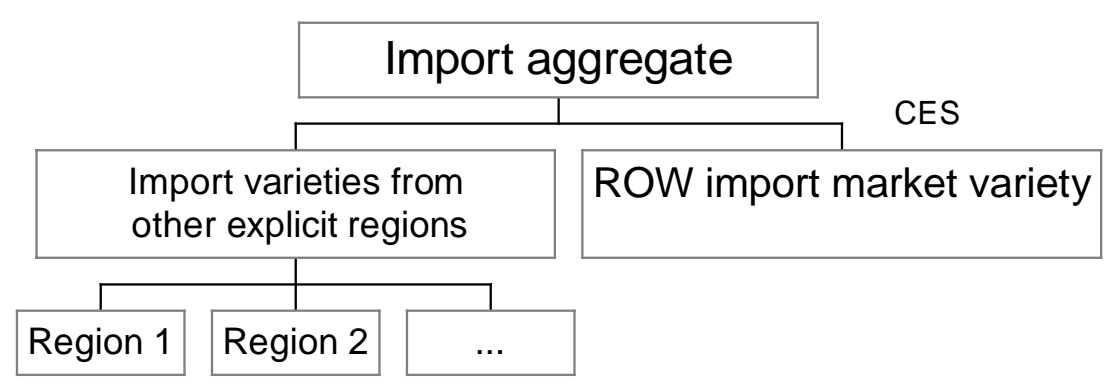

\section{A.3 Implementation of Allowance Allocation Rules}

In our simulations on alternative allowance allocation rules, the price of a unit of $\mathrm{CO}_{2}$ for an industry $i$ or the household $C$ depends on (i) whether we consider an open trading system or a closed trading system, and (ii) whether the respective segment of the economy is eligible for carbon trade (denoted $T$ ). To distinguish carbon prices by sector, we must explicitly account for carbon demands within the zero-profit conditions characterizing the sector-specific energy aggregate and the household energy aggregate (instead of the Armington aggregate). Carbon demands by segments $i$ or $C$ then reads as:

$$
C O 2_{i r}=E_{i r} \sum_{j \in f f} \frac{\partial \Pi_{i r}^{E}}{\partial\left(p_{j r}+a_{j}^{C O 2} p_{j r}^{C O 2}\right)} \text { and } C O 2_{C r}=E_{C r} \sum_{j \in f f} \frac{\partial \Pi_{r}^{C}}{\partial\left(p_{j r}+a_{j}^{C O 2} p_{j r}^{C O 2}\right)} .
$$

\section{A.3.1 Closed System}

For the closed system, the market clearance conditions that determine the carbon prices for segments $\mathrm{z}(z \in\{i, C\})$ can be written as:

$$
\overline{C O 2}_{r}^{T} \geq \sum_{z \in T} C O 2_{z r} \text { and } \overline{C O 2}_{r}-\overline{C O}_{r}^{T} \geq \sum_{z \notin T} C O 2_{z r}
$$

where $\overline{C O 2}_{r}^{T}\left(0<\overline{C O 2}_{r}^{T}<\overline{C O 2}_{r}\right)$ denotes the amount of emission allowances set aside for the segments forming part of the trading system $(T)$. 


\section{A.3.2 Open System}

For the open system, allowances can be traded internationally at an exogenous world market price. In the algebraic formulation, two additional zero profit conditions must be added to specify carbon import activities $I_{z_{r}}^{\mathrm{CO} 2}$ and carbon export activities $E X_{z r}^{\mathrm{CO} 2}$ for segments $z$ of the economy that are open to international trade ( $z \in T$ ):

$$
\bar{e} p^{W} \geq p_{z r}^{C O 2} \quad \text { (imports) and } p_{z r}^{C O 2} \leq \bar{e} p^{W} \text { (exports) }
$$

where $\bar{e} p^{W}$ denotes the international price for a unit of $\mathrm{CO}_{2}$ in domestic currency. Revenues from exports of emission allowances or, likewise, expenditures for imports of carbon emission rights enter the balance of payment constraints.

In the open system, the market clearance condition for those segments that form part of allowance trading reads as:

$$
\overline{C O 2}_{r}^{T} \geq \sum_{z \in T}\left(C O 2_{z r}+I M_{z r}-E X_{z r}\right)
$$

\section{A.3.3 Allocation of Allowances}

We distinguish three rules how emission allowances are assigned to different segments of the economy: (i) auctioning, (ii) emission-based assignment, and (iii) outputbased assignment. Our exposition of generic equilibrium conditions in sections A.2 and A.3 cover the case of (non-distortionary) auctioning. Under emission-based or output-based assignment, the value of freely allocated emission rights constitutes a subsidy that enters the zero-profit condition of sectoral production.

For the output-based rule, where allowances per-unit of output are allocated to eligible sectors in proportion to the benchmark emission intensity $\frac{\bar{E}_{i r}}{\bar{Y}_{i r}}$ the implicit advalorem output subsidy $s_{i r}$ can be written as:

$$
s_{i r} \geq \lambda_{r}^{Y}\left(\frac{\bar{E}_{i r}}{\bar{Y}_{i r}} p_{i r}^{C O 2}\right) / p_{i r},
$$

where $\lambda_{r}^{Y}$ denotes the endogenous average emission assignment factor per unit of output. This factor is determined by the associated "emission budget" constraint:

$$
\overline{C O 2}_{r}^{T} \geq \lambda_{r}^{Y} \sum_{i \in T} \frac{\bar{E}_{i r}}{\bar{Y}_{i r}} Y_{i r} .
$$


For the emission-based rule, where allowances per-unit of output are allocated to eligible sectors in proportion to their emissions $C O 2_{i r}$ the equivalent input subsidy $\tau_{i r}{ }_{r}$ reads as:

$$
\tau_{i r}=\lambda_{r}^{E}
$$

where $\lambda_{r}^{E}$ denotes the endogenous average emission assignment factor per unit of emission.

This factor is determined by the associated "emission budget" constraint:

$$
\overline{\mathrm{CO}}_{r}^{T} \geq \lambda_{r}^{E} \sum_{i \in T} C O 2_{i r} .
$$




\section{Appendix B: Sensitivity Analysis}

\section{B.1 Reduction Targets - Closed System Case}

Figure B.1a: Adjustment cost - Germany (DEU)

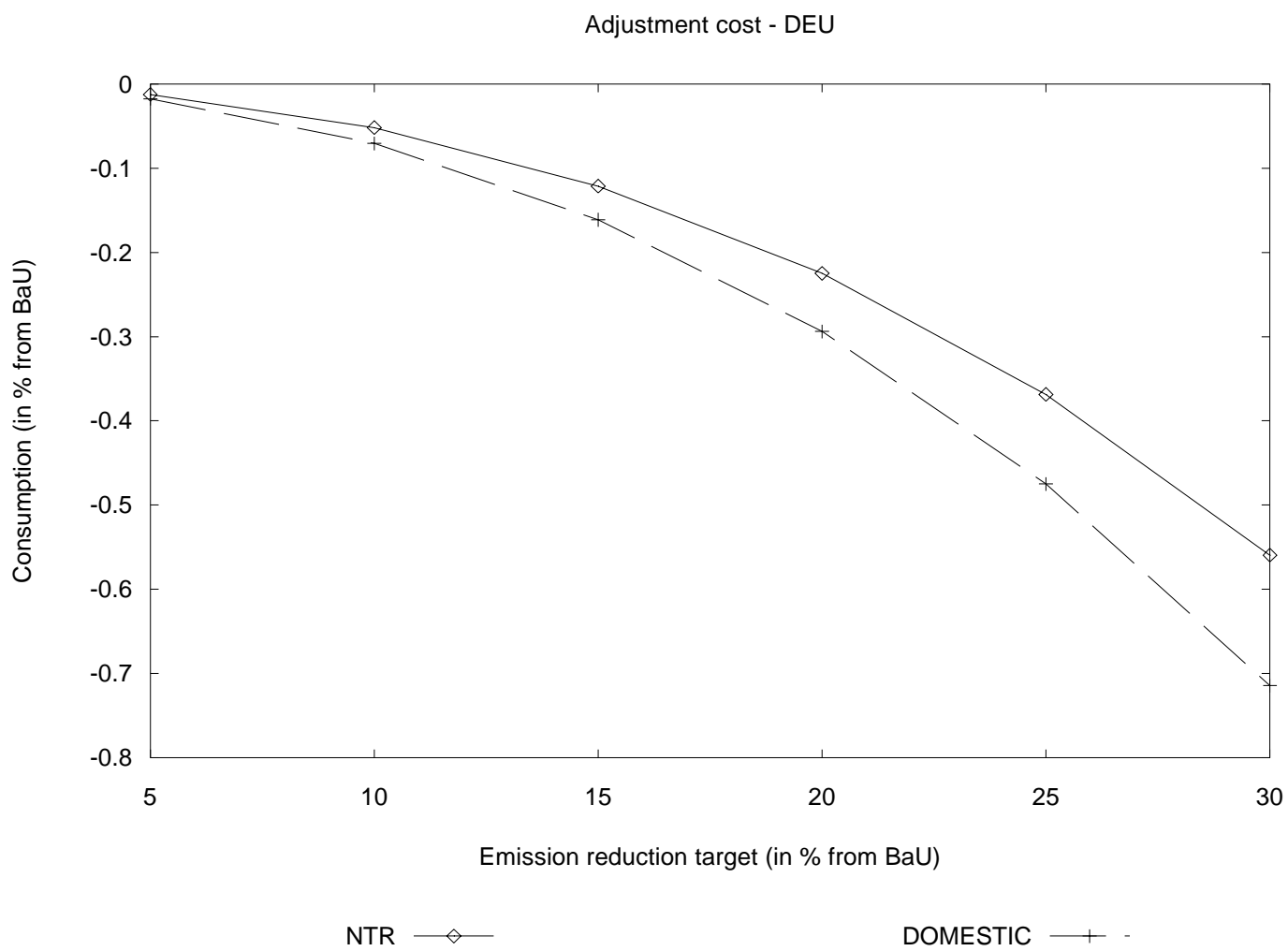

Figure B.1b: Employment in energy-intensive industries - Germany (DEU)

Employment in EIS - DEU

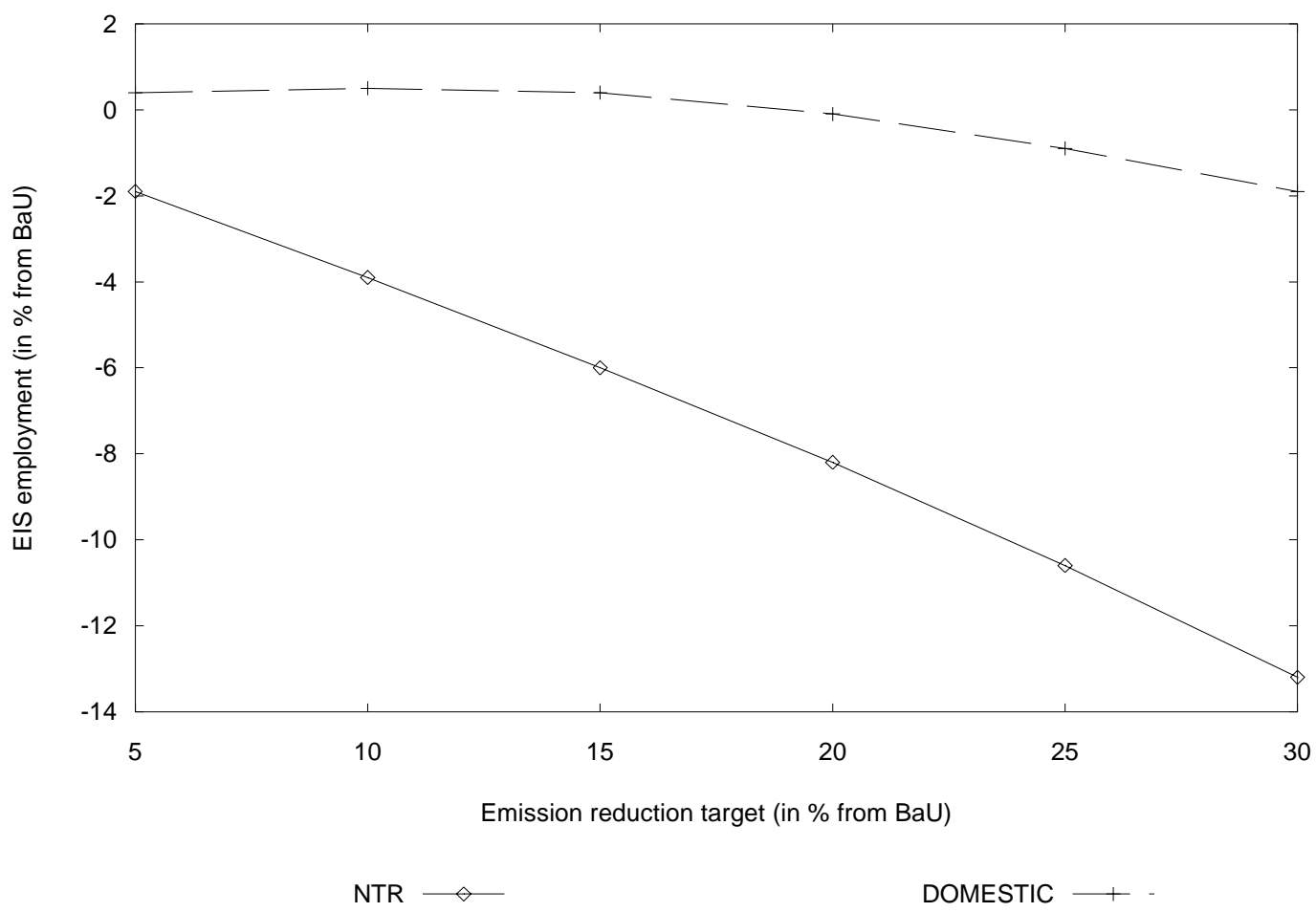




\section{B.2 Benchmark Data}

Figure B.2.1a: Adjustment cost - USA

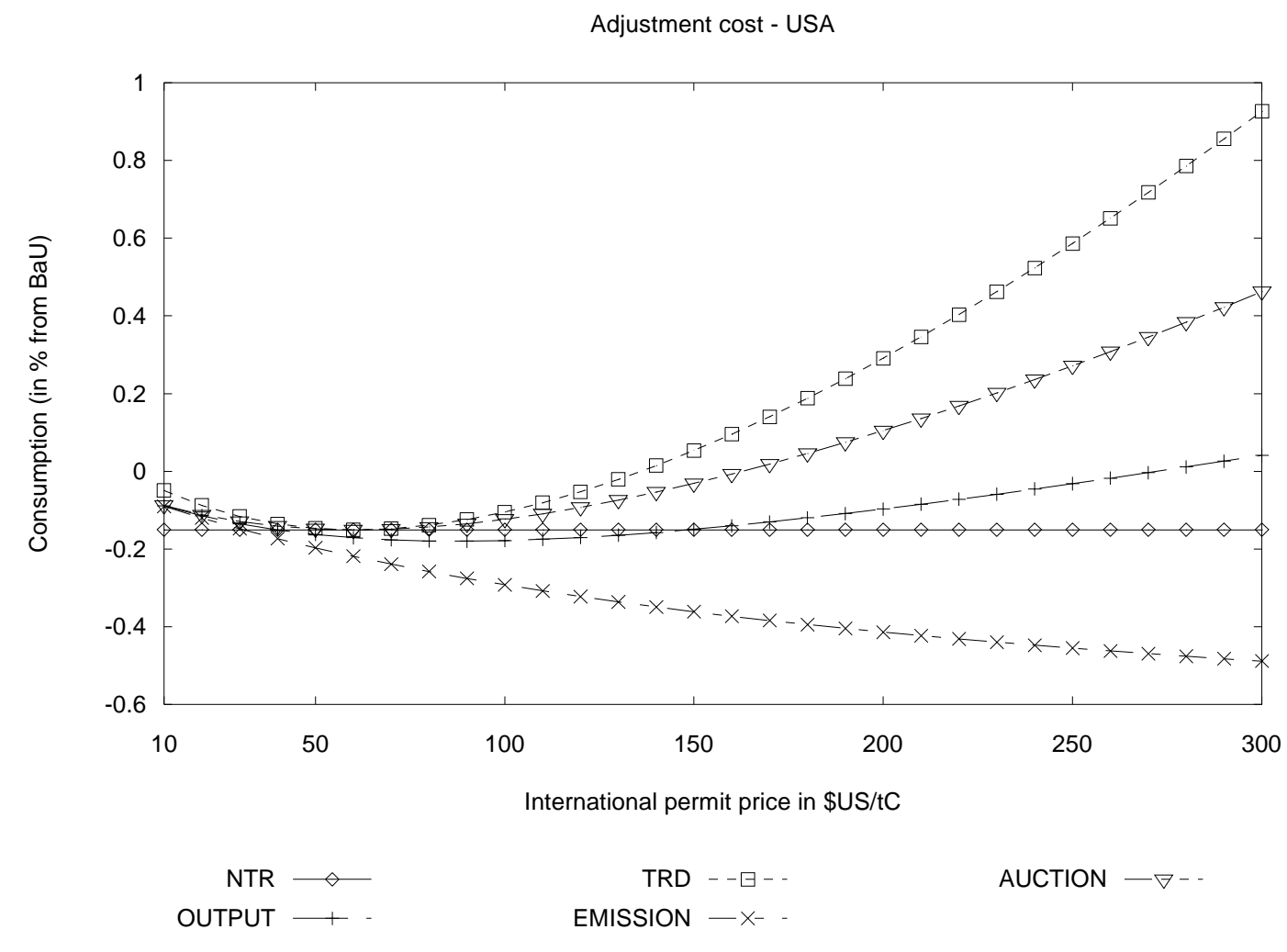

Figure B.2.1b: Employment in energy-intensive industries - USA

Employment in EIS - USA

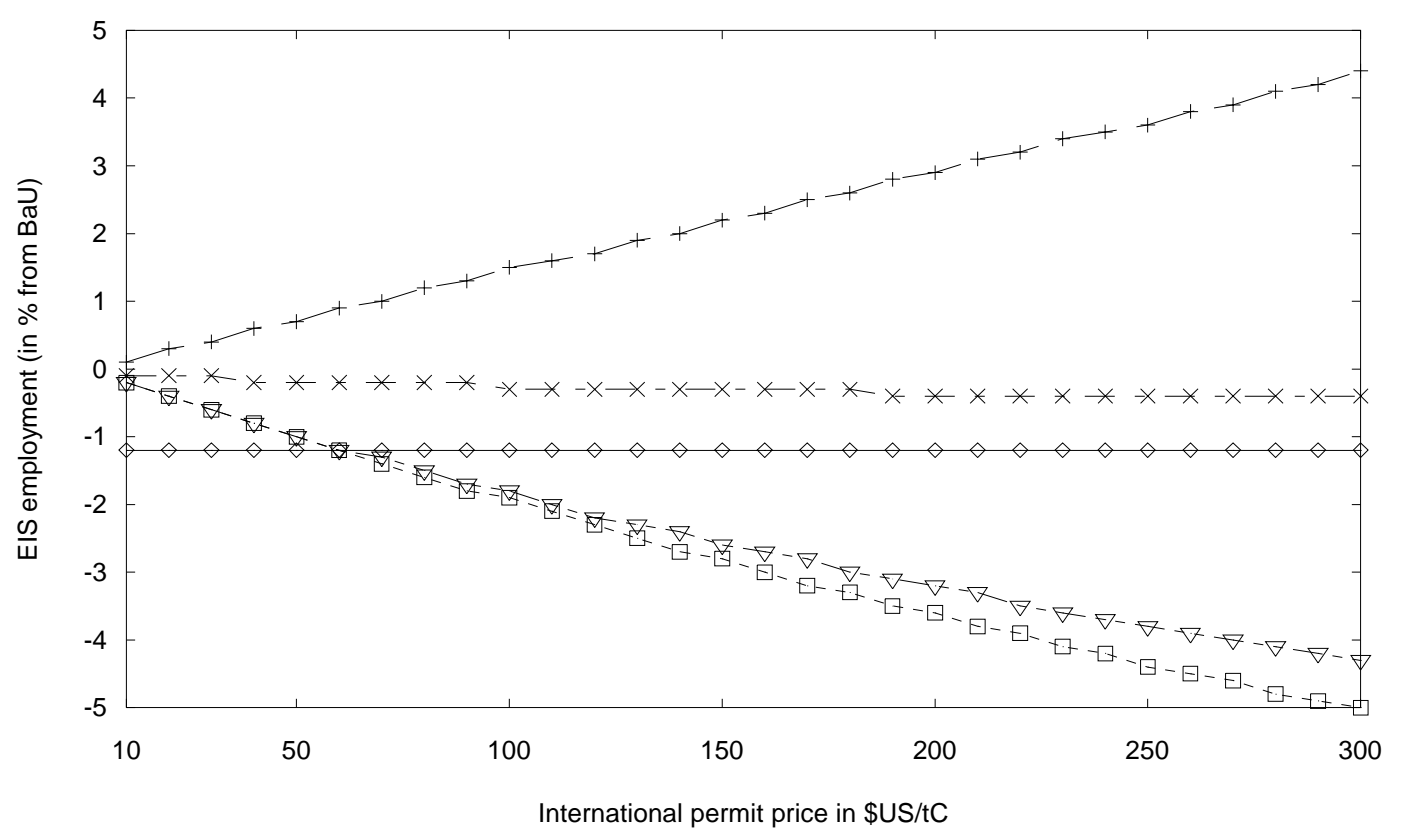

\begin{tabular}{|c|c|c|}
\hline NTR $\diamond$ & TRD $--\boxminus--$ & AUCTION $-\nabla-\cdot$ \\
\hline OUTPUT +- & EMISSION $-x-$ & \\
\hline
\end{tabular}


Figure B.2.2a: Adjustment cost - Japan (JPN)

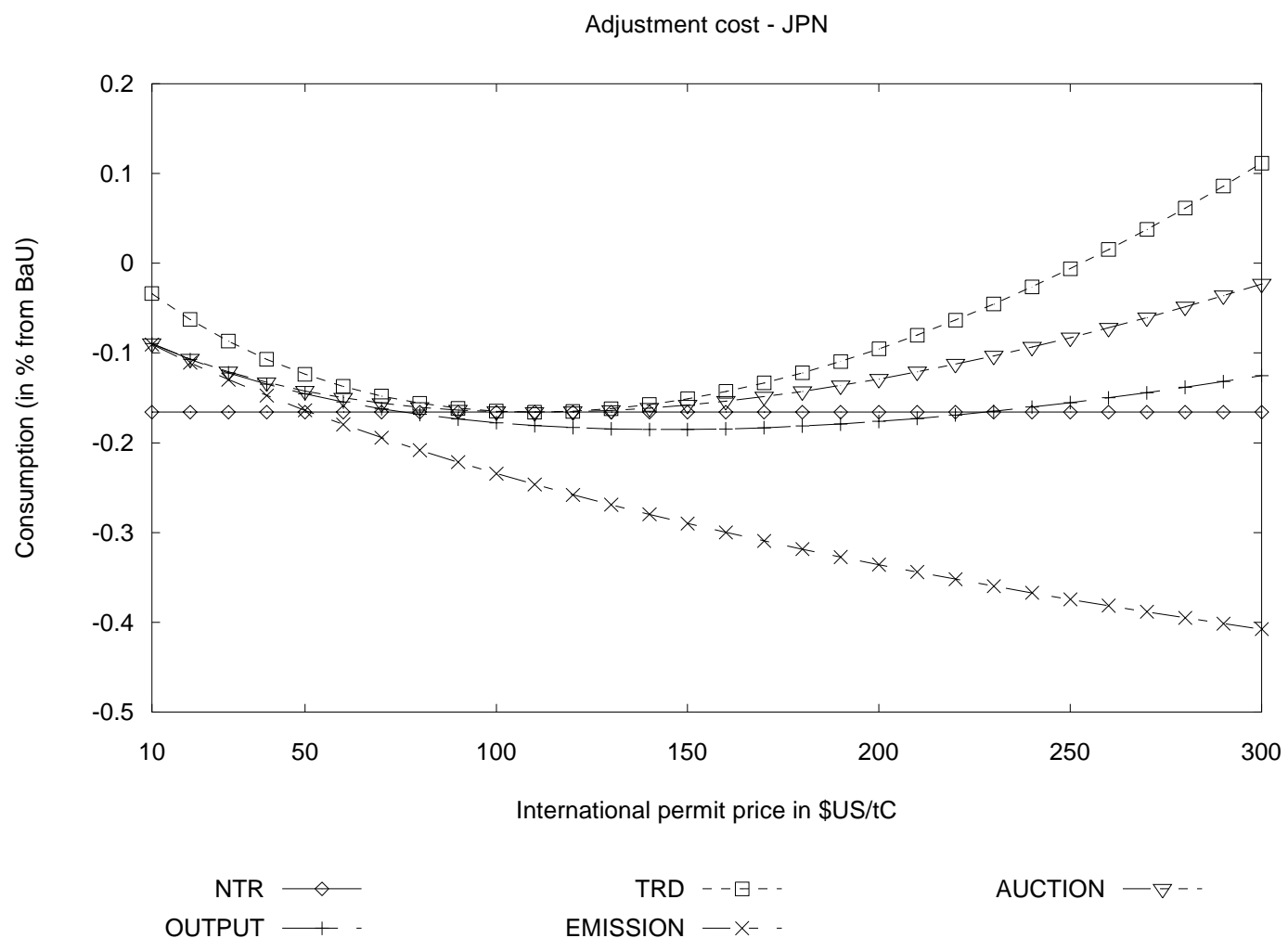

Figure B.2.2b: Employment in energy-intensive industries - Japan (JPN)

Employment in EIS - JPN

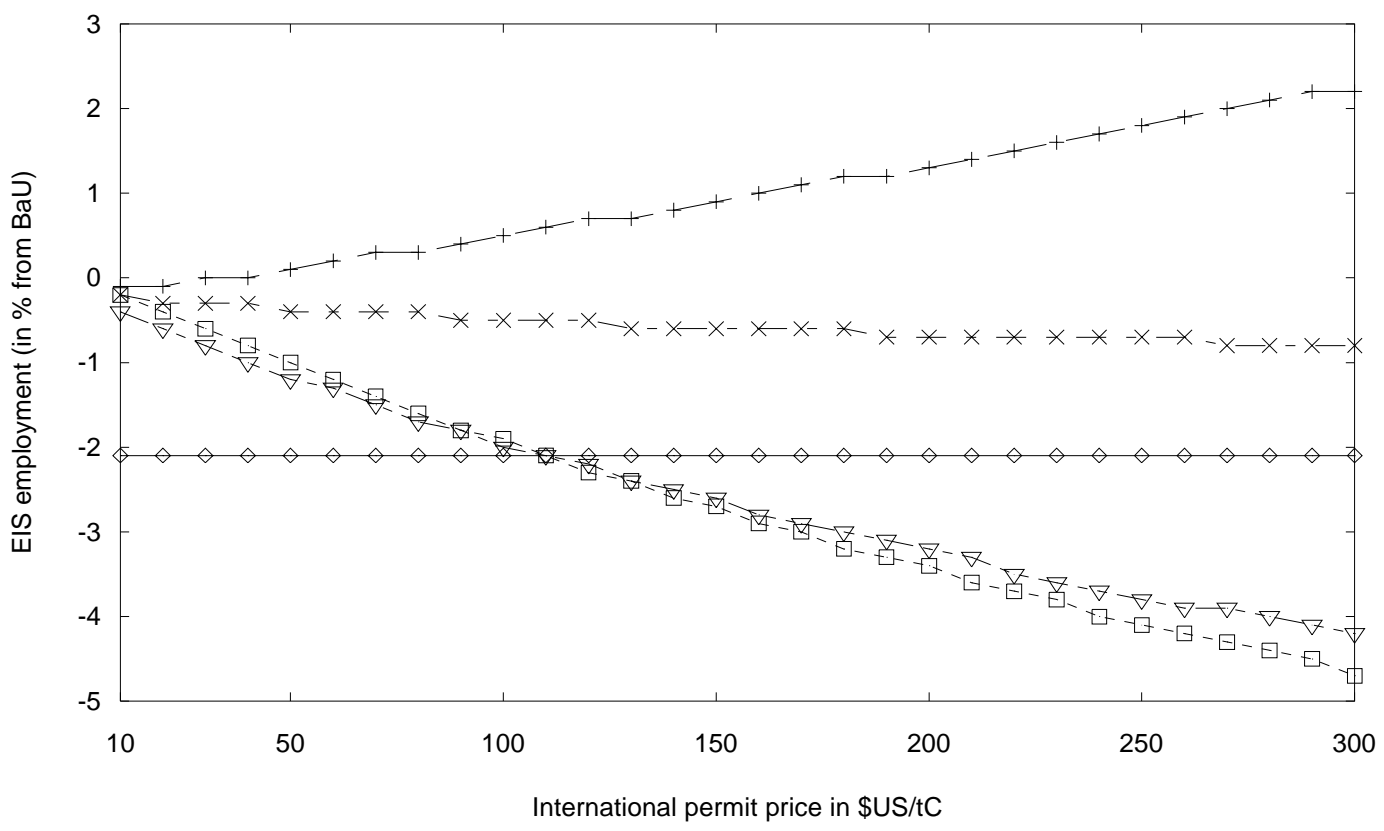

NTR $\diamond$ TRD $-\square^{--}$AUCTION $-\nabla^{--}$ 
Figure B.2.3a: Adjustment cost - Great Britain (GBR)

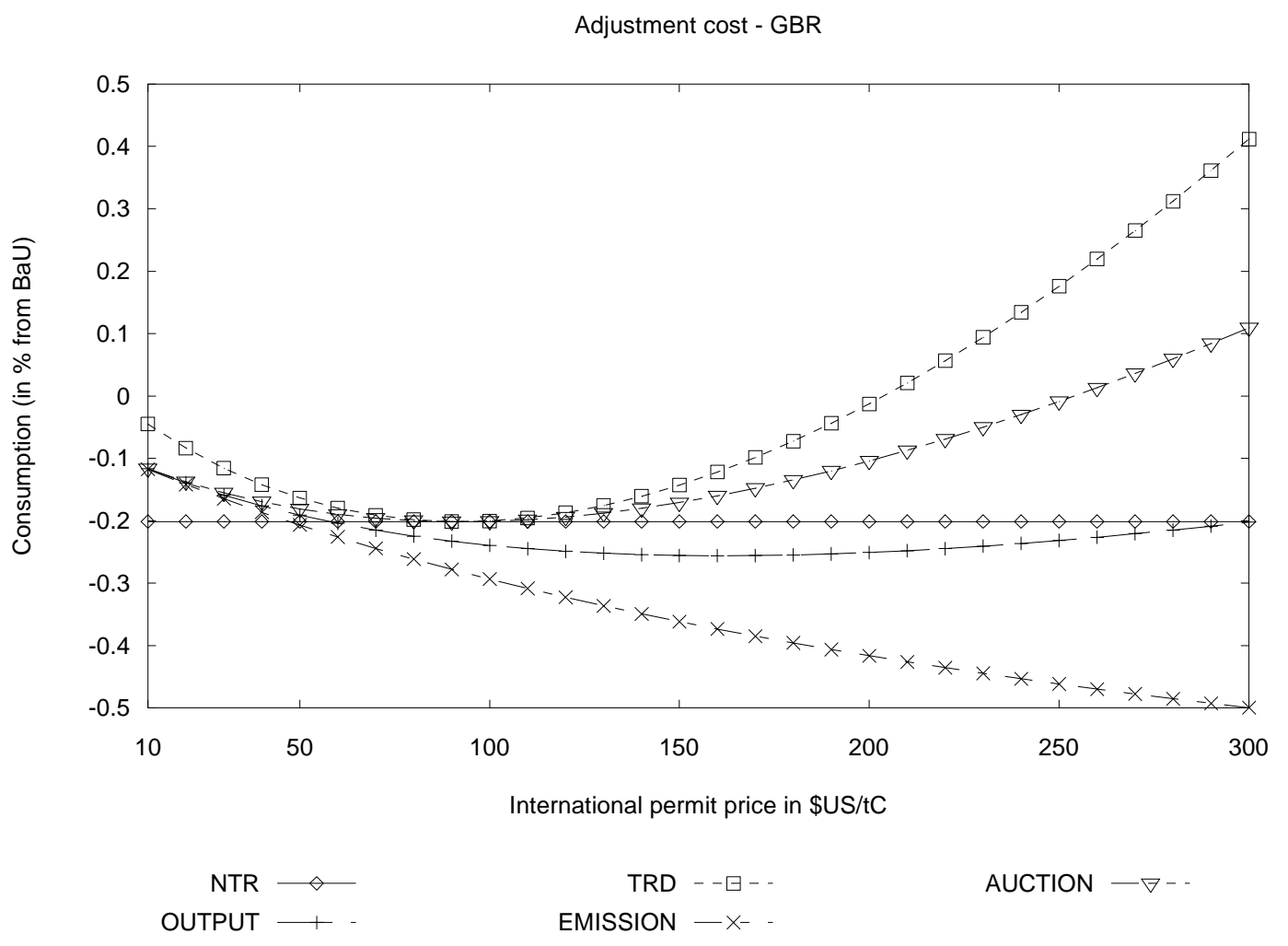

Figure B.2.3b: Employment in energy-intensive industries - Great Britain (GBR)

Employment in EIS - GBR

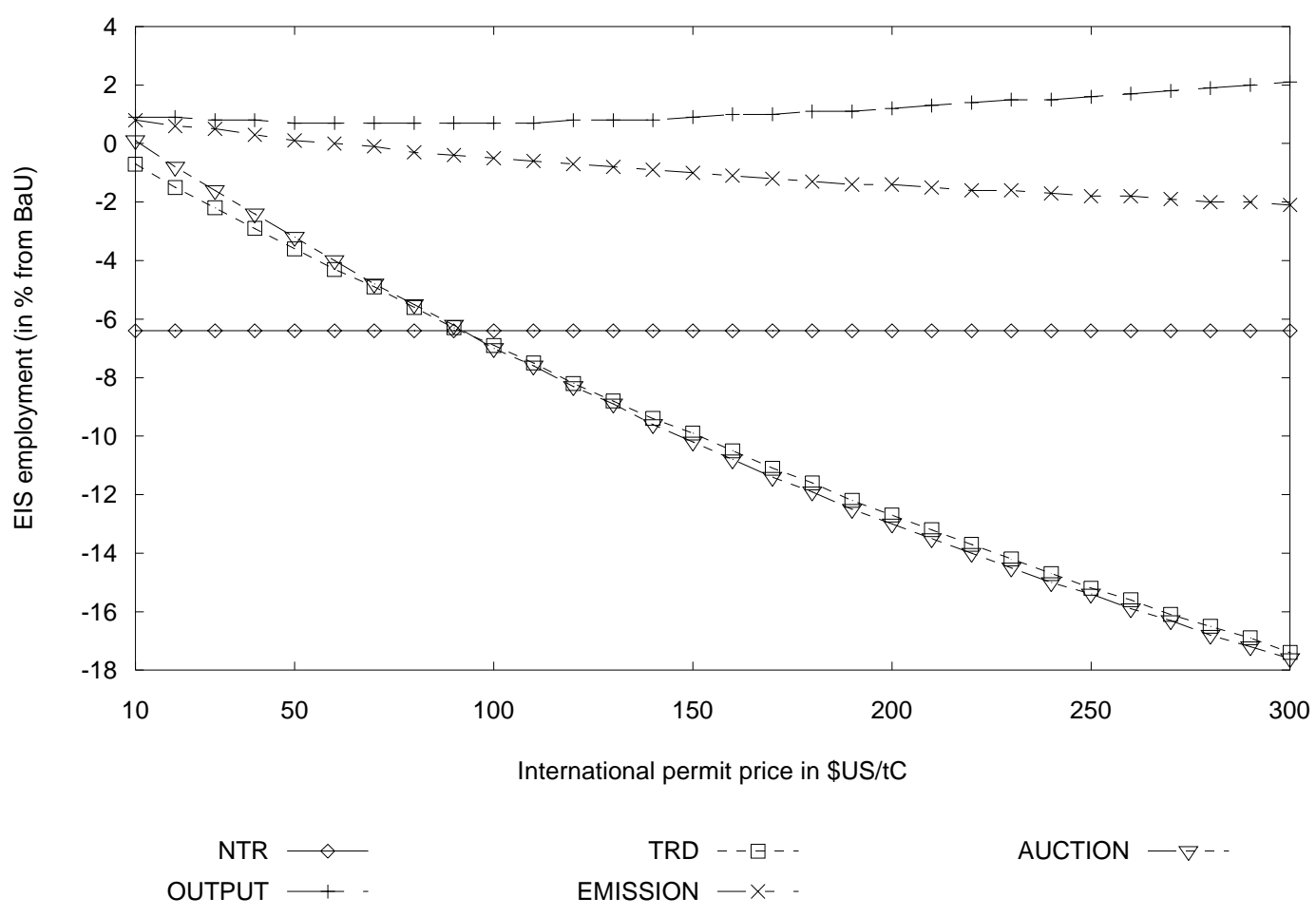


Figure B.2.4a: Adjustment cost - France (FRA)

Adjustment cost - FRA

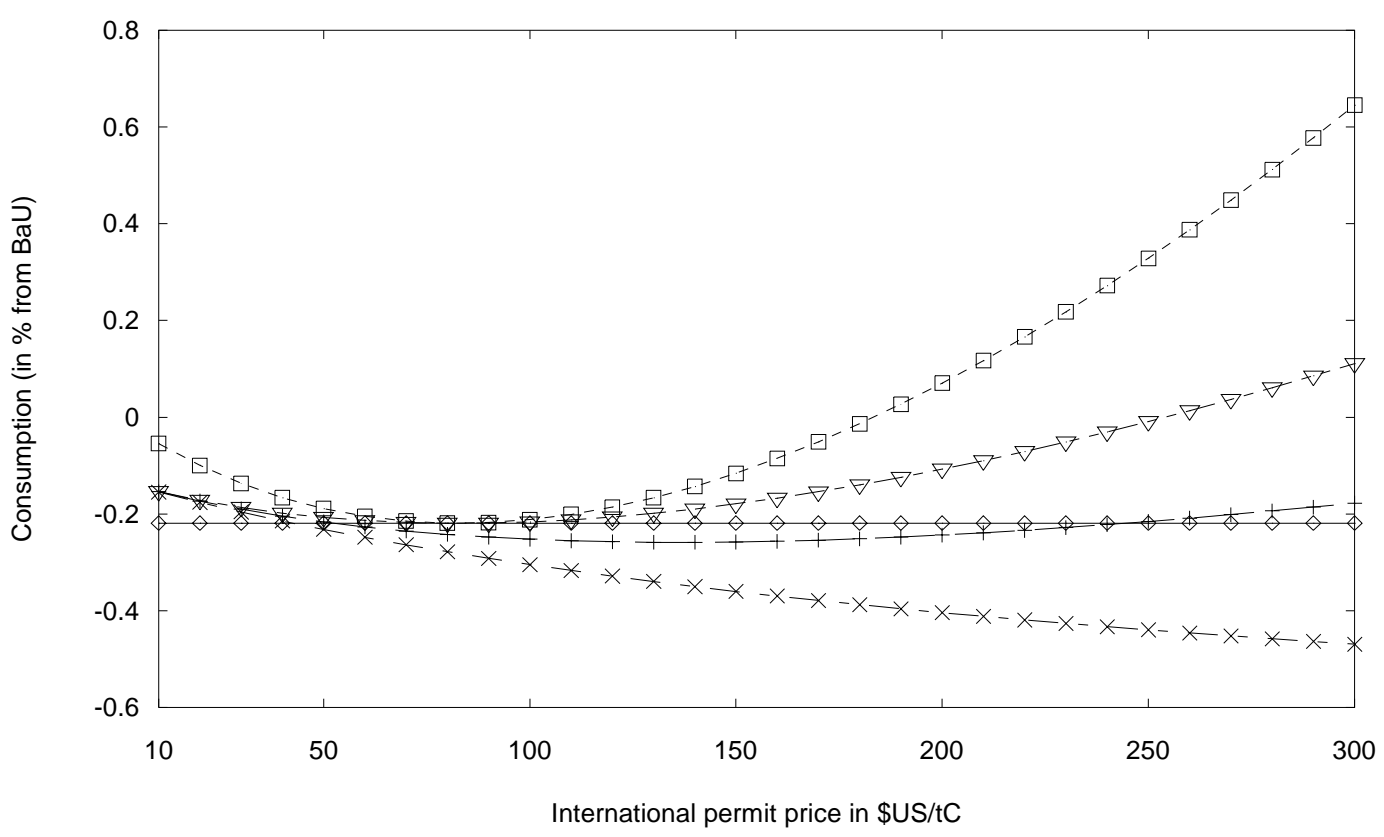

NTR $\diamond \quad$ TRD $--\square_{--} \quad$ AUCTION $-\nabla-$

OUTPUT + EMISSION $-x_{-}$

Figure B.2.4b: Employment in energy-intensive industries - France (FRA)

Employment in EIS - FRA

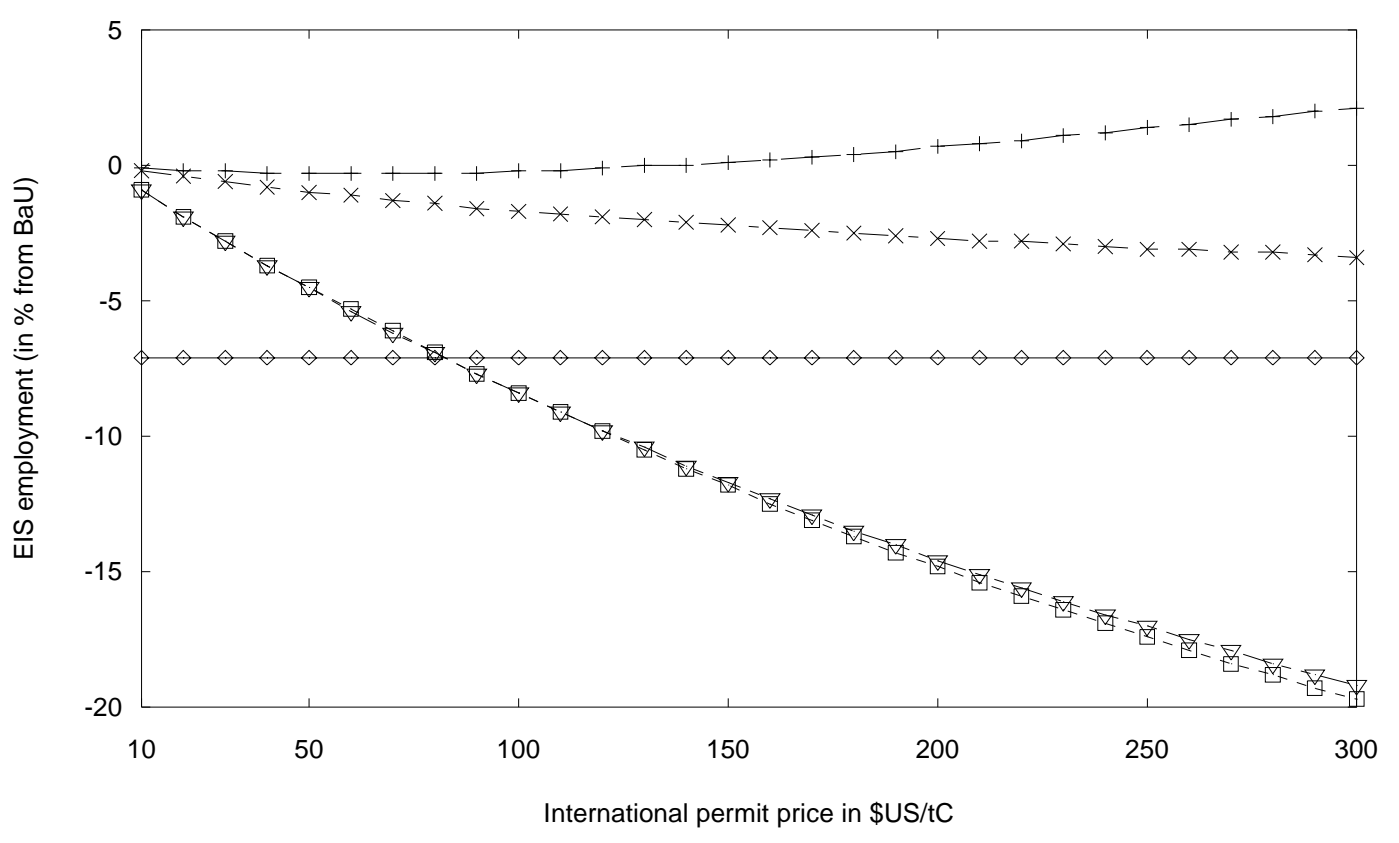

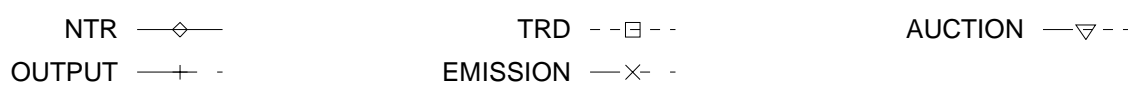


Figure B.2.5a: Adjustment cost - Spain (ESP)

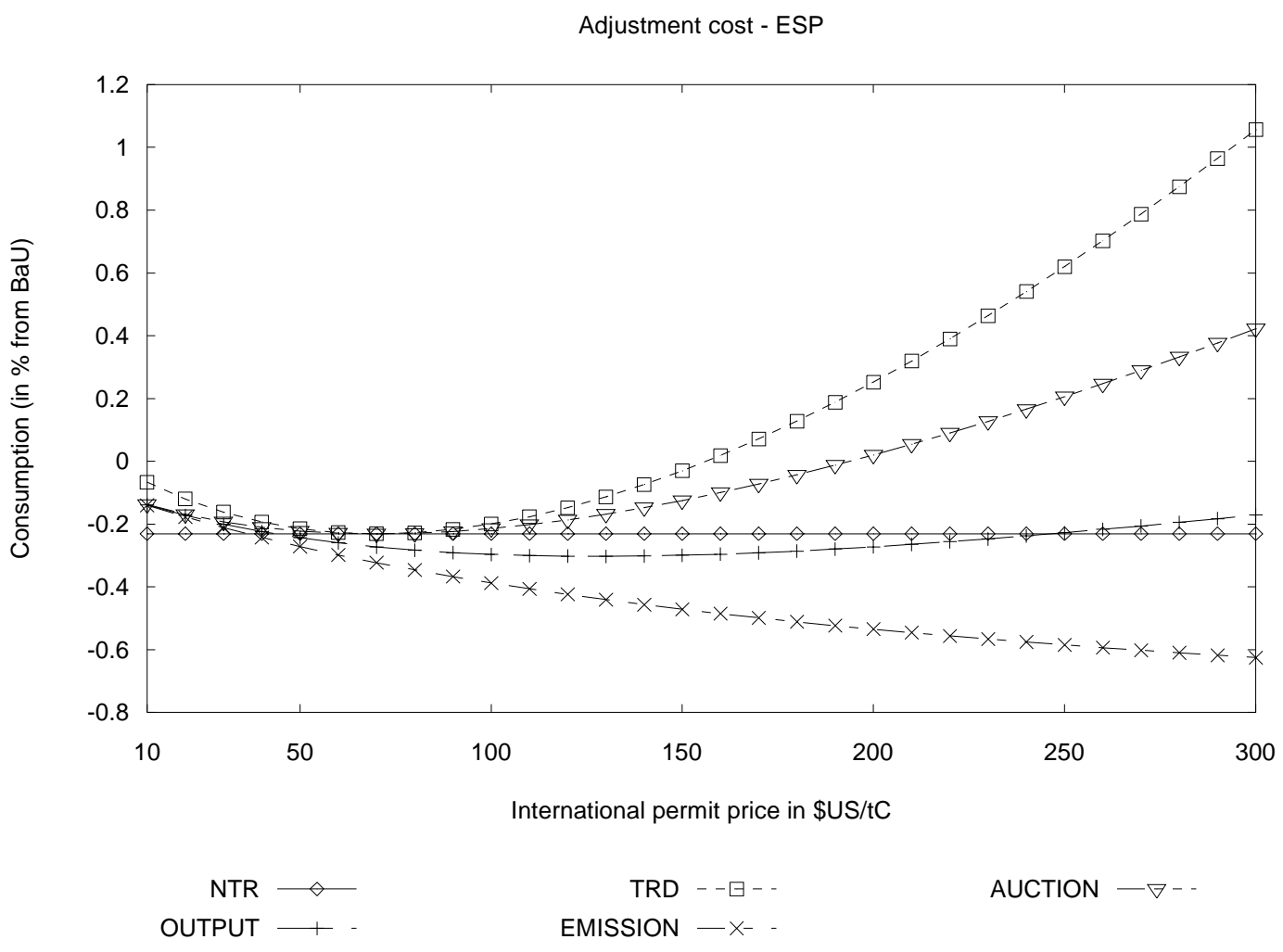

Figure B.2.5b: Employment in energy-intensive industries - Spain (ESP)

Employment in EIS - ESP

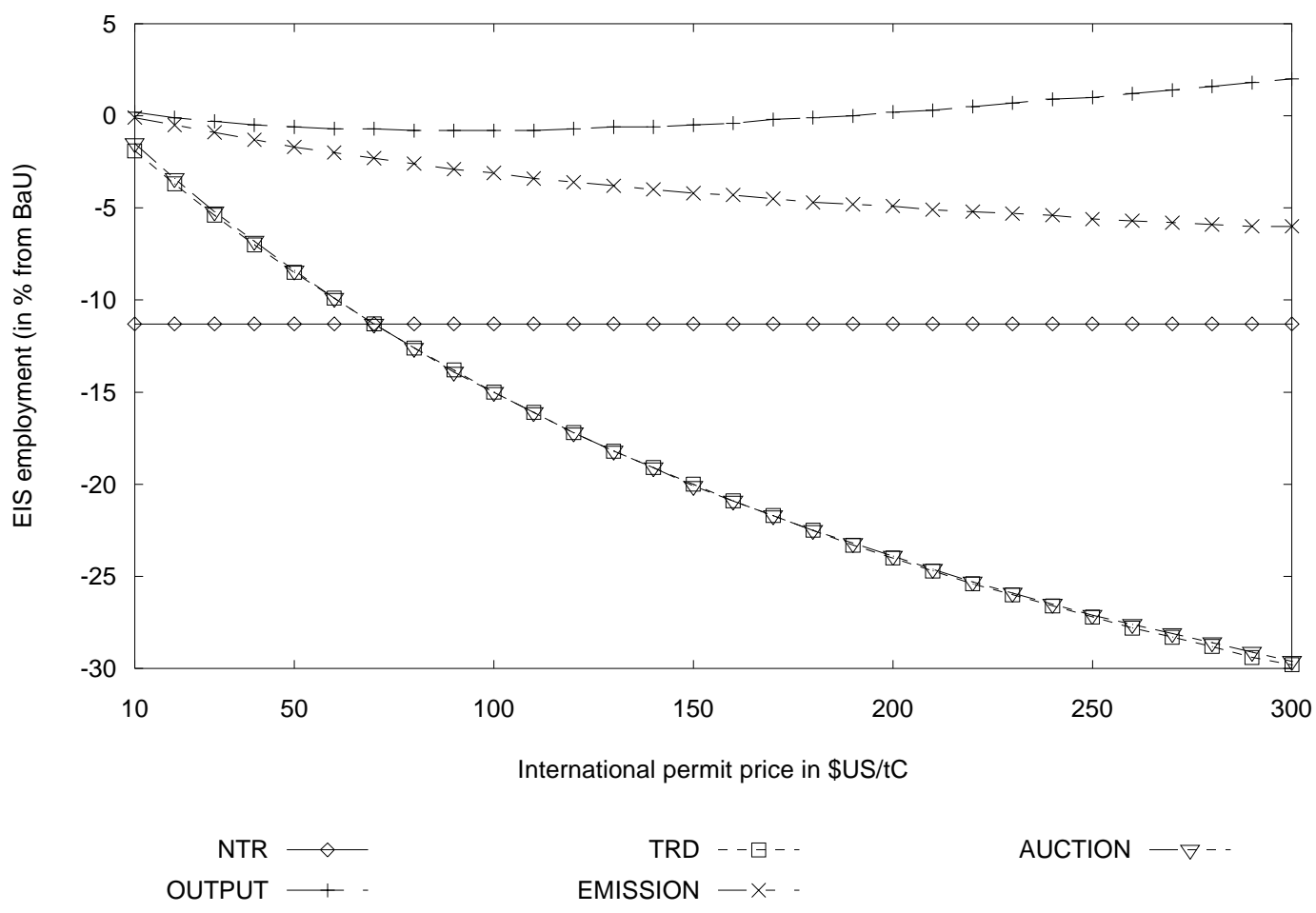


Figure B.2.6a: Adjustment cost - Italy (ITA)

Adjustment cost - ITA

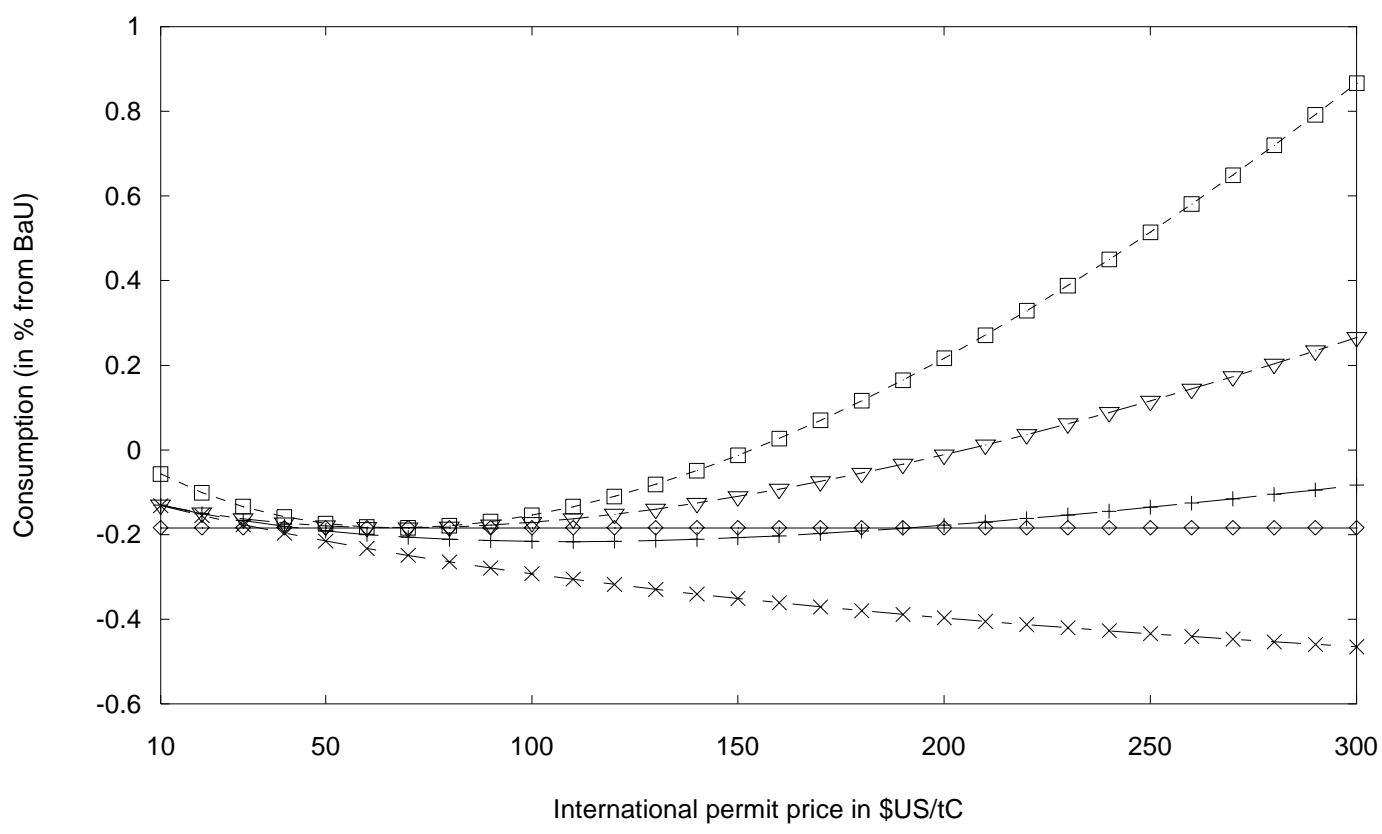

NTR $\triangle \quad$ TRD $--\square_{--} \quad$ AUCTION $-\nabla-$

OUTPUT + EMISSION $-x_{-}^{-}$

Figure B.2.6b: Employment in energy-intensive industries - Italy (ITA)

Employment in EIS - ITA

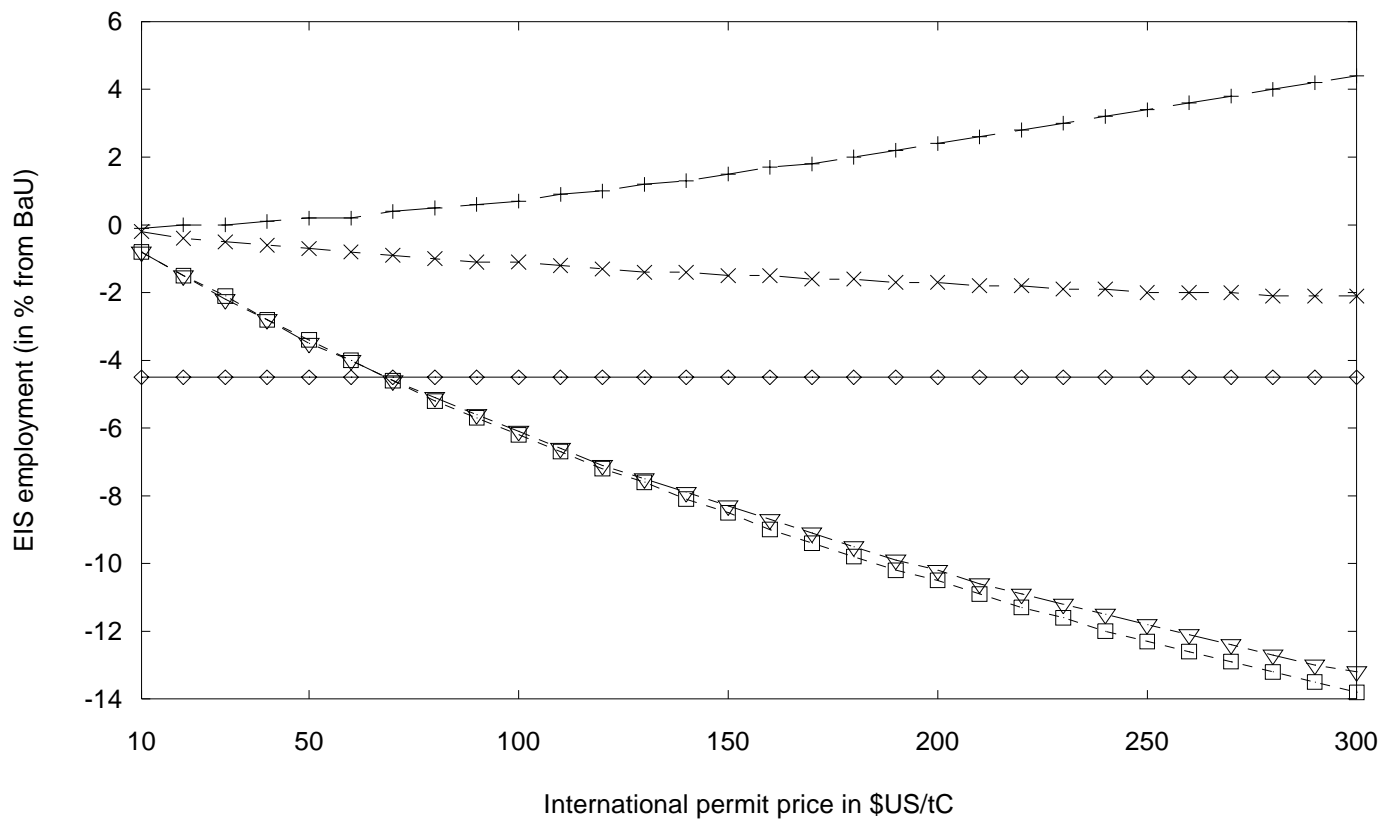

NTR

TRD

AUCTION $-\nabla$ 